This item was submitted to Loughborough's Research Repository by the author.

Items in Figshare are protected by copyright, with all rights reserved, unless otherwise indicated.

\title{
Effects of biaxial confinement in mortars exposed to external sulfate attack
}

PLEASE CITE THE PUBLISHED VERSION

https://doi.org/10.1016/j.cemconcomp.2018.10.017

\section{PUBLISHER}

(c) Elsevier

\section{VERSION}

AM (Accepted Manuscript)

\section{PUBLISHER STATEMENT}

This paper was accepted for publication in the journal Cement and Concrete Composites and the definitive published version is available at https://doi.org/10.1016/j.cemconcomp.2018.10.017

\section{LICENCE}

CC BY-NC-ND 4.0

\section{REPOSITORY RECORD}

Ikumi, Tai, Ignacio Segura, and Sergio Pialarissi-Cavalaro. 2019. "Effects of Biaxial Confinement in Mortars Exposed to External Sulfate Attack”. figshare. https://hdl.handle.net/2134/36714. 
EFFECTS OF BIAXIAL CONFINEMENT IN MORTARS EXPOSED TO EXTERNAL 2 SULFATE ATTACK

Tai Ikumi ${ }^{\mathrm{a}, *}$, Ignacio Segura ${ }^{\mathrm{a}, \mathrm{b}}$ and Sergio H. P. Cavalaro ${ }^{\mathrm{c}}$

${ }^{a}$ Department of Civil and Environmental Engineering, Universitat Politècnica de Catalunya Barcelona Tech, Jordi Girona 1-3, C1, E-08034 Barcelona, Spain

${ }^{\mathrm{b}}$ Smart Engineering, Jordi Girona 1-3 K2M 202c, Barcelona, Spain

${ }^{\mathrm{c}}$ School of Architecture, Building and Civil Engineering, Loughborough University,

10 Leicestershire, LE11 3TU, United Kingdom

11 * Corresponding authors: Department of Civil and Environmental Engineering, Universitat

12 Politècnica de Catalunya Barcelona Tech, Jordi Girona 1-3, C1, E-08034 Barcelona, Spain.

13 Email addresses: tai.ikumi@upc.edu (T. Ikumi)

14 Tel: +34934016507 Fax: +34934011036.

\section{ABSTRACT}

Research on external sulfate attack (ESA) is usually performed on small scale specimens under free expanding conditions. However, most field structures cannot expand freely due to confinement induced by the ground or other elements from the structure. As a result, ESA usually develops in confined conditions. This work aims to assess the interaction of gradual biaxial compression stresses generated by confinement with the ESA. Visual appearance, mass and ultrasonic velocity were monitored to characterize the macro-scale behavior of free and restrained mortar samples. Changes on phase composition and crystal morphology induced by confinement were evaluated by X-Ray diffraction and scanning electron microscopy. The confining stresses generated were estimated during the attack. Results indicate that ESA is not developed equally in free and confined specimens. The confinement limits sulfate availability, reduce the amount of ettringite precipitated and might induce changes on crystal morphology that reduce the degradation caused by the ESA.

Keywords: Concrete (E); Durability (C); Sulfate attack (C); Ettringite (D); Confinement;

\section{INTRODUCTION}

External sulfate attack (ESA) is a degradation process that affects concrete structures. It is caused by the interaction between the reactive phases of the cement paste and sulfate ions from an external source. The continuous sulfate exposure may lead to cracking, spalling, softening and disintegration. Fortunately, in typical service conditions the attack usually develops during decades before causing high degrees of damage. 
The majority of common methods to investigate the resistance of cement-based materials exposed to sulfates are based on accelerated tests to obtain representative results in a reasonable time (e.g. ASTM C1012 or ASTM C452). These test methods assess the sulfate resistance by length change measurements of unconfined specimens submerged in sulfate rich solutions. As a result, most research carried out in this field use free expansions as the main degradation parameter. However, typical elements exposed to ESA, such as foundations or retaining walls, can rarely expand freely during sulfate exposure. Instead, these elements are subjected to a wide variety of external loads and to different degrees of confinement due to interactions with other elements of the structure and the soil.

Most studies dealing with the coupled action of external loads and ESA apply a constant flexural or compressive load since sulfate exposure [1-9]. In general, flexural loading applied together with the sulfate exposure resulted in negative effects on the durability against the attack, especially when the loading exceeded $40-60 \%$ of the maximum flexural load [7,8]. R. Gao et. al [7] reported more serious deterioration of the face subjected to tensile stresses than the one subjected to compressive stresses. According to the authors [7], the tensile stresses might accelerate the sulfate attack due to micro-cracks that promote sulfate penetration.

Fewer studies are available in the literature dealing with the combined action of sulfate attack and compressive loading [1-3,9]. This is probably caused by the higher complexity of the experimental set up. In general, studies report favorable effects on the durability against the attack for low stress levels, as it might slow down the sulfate ingress into concrete. However, compressive stresses seems to accelerate the sulfate attack when the stress is set above a certain threshold value, estimated between the $30-60 \%$ of the ultimate compressive strength. This acceleration is attributed to the generation of micro-cracks that promotes sulfate penetration [1$3,9]$.

In all studies presented above, the load was applied from exposure and remained constant until the end of the test. Although this configuration might simulate the effects of underground water, rocks, overlaying soil or dead loads from the superstructure, it does not represent the effects of confinement that might appear in indeterminate structures. In this case, the load rises as a consequence of the expansions generated by the ESA, thus increasing gradually along the attack. Figure 1 illustrates this situation with a group of end bearing piles joined at the top by a pile cap. Due to the heterogenic characteristics of the groundwater level and the distribution of gypsum veins in the soil, the expansions generated by the attack $\left(\varepsilon_{E S A}\right)$ evolve at different rates at each pile. However, highly indeterminate structures act as a single entity prior to failure. Consequently, the least affected elements (pile 2 and 3) restraint the expansions and confine the concrete of pile 1 by applying a gradual compressive load $\left(\mathrm{F}_{\mathrm{c}}\right)$ in the whole section. 


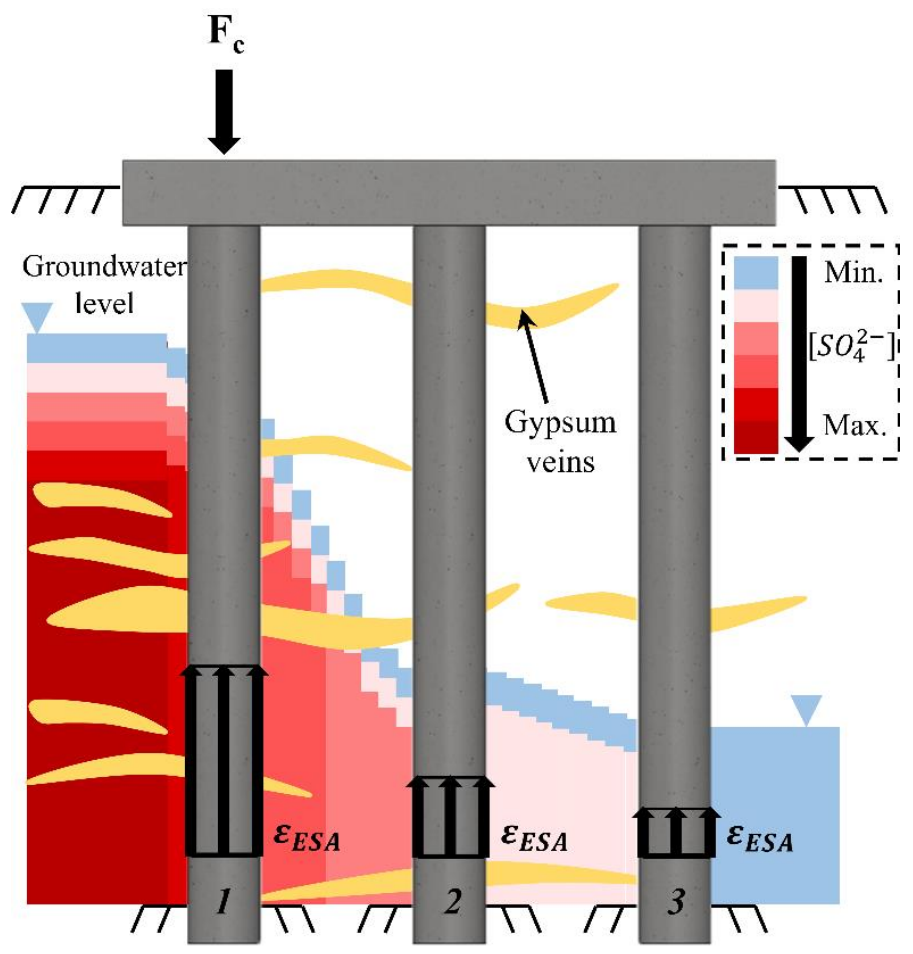

Previous research on the interaction between constant compressive loads and ESA [1-3,9] suggests that the effects of confinement will probably depend on the stress level. Therefore, for a precise assessment of this phenomenon, it is necessary to link the different behavior of confined and free specimens with the stress level applied. The monitoring of the confining stresses generated during the attack requires complex experimental set ups. Only one study was found in the literature able to capture this phenomenon [10]. Mullauer et. al [10] applied different degrees of confinement to thin-walled mortar cylinders exposed to sulfates by a specially constructed stress cell. Even though the main objective was to estimate the stresses generated during the attack, it indirectly pointed some possible positive effects of confinement on the durability. Evolution of the phase composition with and without confinement showed that both ettringite and gypsum were partially suppressed at late stages of the attack by increasing the degree of confinement. Unfortunately, other potential effects of stresses generated by confinement remain practically unexplored and are ignored during the assessment of the ESA. The present work aims to shed light on this phenomenon and identify which processes (ionic transport, phase composition or crystal morphology) might be altered by the confining stresses.

One of the key aspects to study this phenomenon is the experimental set up adopted to generate the confinement. In this work, the confinement is achieved by casting mortar specimens in the shape of flattened cylinders within metallic rings. To increase the representativeness of this study, 6 mortar compositions with different expansive potentials are considered to induce varying magnitudes of confining stresses. Stresses are estimated by the monitoring of expansions in restrained specimens throughout the attack. Visual appearance, mass and ultrasonic velocity 
104 variations are used to characterize the macro-scale behavior of free and restrained samples.

105 Changes on phase composition and crystal morphology are evaluated by X-Ray diffraction with

106 Rietveld refinement and scanning electron microscopy with energy dispersive X-ray analysis,

107 respectively.

This study describes how the confined conditions in which ESA usually develops reduce the deleterious effects associated to the attack. The understanding of the positive effects of

111 confinement could lead to more realistic assessments of the ESA and contribute to explain the

112 large difference between the damage developed in small-scale free-expanding laboratory

113 specimens and the one observed in real structures.

\section{EXPERIMENTAL PROGRAM}

\subsection{MATERIALS AND MIXTURE CHARACTERISTICS}

Materials and mixture characteristics were defined to obtain mortars with different expansion rates to assess the effects of confinement over a wide range of confining stresses. Two different Portland cements were used as binders: ordinary CEM I 52.5R (OPC) and sulfate-resisting CEM I 42.5 R-SR5 (SRPC). Moreover, a low-calcium fly ash (ASTM C618 class F) and the airentrainer MasterAir 100 were incorporated in some dosages. Table 1 shows the chemical and mineralogical composition of the binders and summarizes the physical properties. Chemical composition was determined by XRF spectrometry and mineralogical composition was estimated by Bogue equations. Data provided by Bogue equations is only used qualitatively to classify the cements. Due to the presence of ferromagnetic particles, the elemental composition of the fly ash was determined by ICP-MS. Deionized water and siliceous sand following the specifications of UNE-EN 196-1:2005 were used in all mortars. Commercial superplasticizer GLENIUM ACE

130456 was added to the mixtures.

Table 1. Properties of binders.

\begin{tabular}{lcccc}
\hline \hline & $\mathrm{OPC}^{\mathrm{a}}$ & SRPC $^{\mathrm{b}}$ & $\mathrm{FA}^{\mathrm{c}}$ \\
\hline Chemical comp. [\% bcw & & & \\
$\mathrm{SiO}_{2}$ & & & Elemental comp. [\%] & \\
$\mathrm{Al}_{2} \mathrm{O}_{3}$ & 19.50 & 20.80 & $\mathrm{Si}$ & 23.56 \\
$\mathrm{Fe}_{2} \mathrm{O}_{3}$ & 5.90 & 4.00 & $\mathrm{Al}$ & 8.74 \\
$\mathrm{CaO}$ & 1.70 & 4.00 & $\mathrm{Fe}$ & 6.92 \\
$\mathrm{MgO}$ & 63.10 & 62.70 & $\mathrm{Ca}$ & 3.70 \\
$\mathrm{SO}_{3}$ & 2.10 & 1.70 & $\mathrm{Mg}$ & 0.50 \\
$\mathrm{~K}_{2} \mathrm{O}$ & 3.50 & 3.02 & $\mathrm{~S}$ & 0.20 \\
$\mathrm{Na}_{2} \mathrm{O}$ & 0.78 & 0.55 & $\mathrm{~K}$ & 0.55 \\
$\mathrm{Cl}^{-}$ & 0.35 & 0.24 & $\mathrm{Na}$ & - \\
$\mathrm{MnO}^{-}$ & 0.02 & 0.01 & $\mathrm{P}$ & 0.11 \\
$\mathrm{TiO}_{2}$ & - & & $\mathrm{Mn}$ & 0.01 \\
& - & & $\mathrm{Ti}$ & 0.28 \\
\hline
\end{tabular}




\begin{tabular}{lccc}
\hline Physical prop. & & & \\
Spec. surf. area (BET) $\left[\mathrm{m}^{2} / \mathrm{g}\right]$ & 1.10 & 1.16 & 1.56 \\
$\mathrm{~d}_{10}[\mu \mathrm{m}]$ & 0.58 & 0.57 & 2.08 \\
$\mathrm{~d}_{50}[\mu \mathrm{m}]$ & 6.88 & 7.29 & 8.97 \\
$\mathrm{~d}_{90}[\mu \mathrm{m}]$ & 31.84 & 34.92 & 29.21 \\
\hline Phase comp. $\left[\%\right.$ bcw $\left.^{d}\right]$ & & & \\
$\mathrm{C}_{3} \mathrm{~S}$ & 65.4 & 62.1 & \\
$\mathrm{C}_{2} \mathrm{~S}$ & 10.6 & 15.6 & \\
$\mathrm{C}_{3} \mathrm{~A}$ & 12.3 & 4.1 & \\
$\mathrm{C}_{4} \mathrm{AF}$ & 5.6 & 13.6 & \\
\hline \hline
\end{tabular}

a: Ordinary Portland cement, ${ }^{\mathrm{b}}$ : Sulfate-resisting Portland cement, ${ }^{\mathrm{c}}$ : Fly ash and ${ }^{\mathrm{d}}$ :By cement weight.

135 The composition of the 6 matrices used in this study are listed in Table 2. The composition of the

136 OPC_0.45 intends to simulate the typical composition of the mortar that surrounds the coarse

137 aggregate in a conventional concrete applied in foundations. Mortars with high expansive

138 potentials were produced by using OPC with varying water/cement ratios (from 0.38 to 0.55 ) and

139 the use of an air-entrainer to promote sulfate penetration. Fly ash was incorporated in one

140 composition to obtain a highly refined pore network. Volumetric variations caused by the

141 different water/cement ratios considered and the use of fly ash were fully compensated by a

142 reduction of sand, maintaining a constant amount of cement in all compositions. The slight

143 increase of volume produced by the air-entrainer was not taken into account. On the other hand,

144 a dosage with SRPC was designed to assess the behavior of low expansive mortars under

145 confined conditions. The nomenclature adopted for each composition follows the pattern 'cement

146 type' 'water/cement ratio'. Mortars with air-entrainer or fly ash have the term 'AE' or 'FA' after

147 the cement type, respectively.

149 The mixing procedure defined in UNE-EN 196-1:2005 was adopted. In the case of the

150 composition with fly ash, the latter was first thoroughly mixed with cement prior to water

151 addition. The air-entrainer was added at the end of the mixing procedure and mixed at high speed

152 for $60 \mathrm{~s}$. To assure similar surface finish qualities and workability amongst the different

153 compositions, superplasticizer was mixed with the deionized water to obtain flow extents of 20

$154 \mathrm{~cm} \pm 0.5 \mathrm{~cm}$.

Table 2. Compositions and mass attenuation coefficient (MAC) of the mortars.

\begin{tabular}{ccccccc}
\hline \hline Material & OPC_0.38 & OPC_0.45 & OPC_0.55 & OPC+AE_0.45 & OPC+FA_0.45 & SRPC_0.45 \\
\hline Cement $\left[\mathrm{kg} / \mathrm{m}^{3}\right]$ & 580 & 580 & 580 & 580 & 580 & 580 \\
Sand $\left[\mathrm{kg} / \mathrm{m}^{3}\right]$ & 1425 & 1325 & 1180 & 1325 & 1140 & 1330 \\
Water $\left[\mathrm{kg} / \mathrm{m}^{3}\right]$ & 220 & 261 & 319 & 261 & 261 & 261 \\
Water/cement ratio & 0.38 & 0.45 & 0.55 & 0.45 & 0.45 & 0.45 \\
Air-entrainer [\% bcw] & - & - & - & 0.3 & - & - \\
Fly ash [\% bcw] & & & & & 30 & \\
Superplasticizer [\% & 1.00 & 0.35 & - & 0.25 & 0.55 & 0.20 \\
bcw] & & & & & & \\
\hline
\end{tabular}




\subsection{EXPERIMENTAL PROCEDURE}

\subsubsection{SPECIMEN PREPARATION}

Specimens traditionally used for the assessment of the ESA consist of slender prisms with low volume to surface ratios to maximize sulfate ingress and facilitate measurement of expansions. However, the generation of confinement in samples with such geometric characteristics submerged in aggressive solutions requires complex devices with limited accuracy and replicability [1-3,9].

In this work, mortars specimens of $78 \mathrm{~mm}$ of diameter and $17 \mathrm{~mm}$ of height were used. This configuration allows easier expansion restraint by casting the sample within a metallic ring. The dimensions of the mortar specimens were defined to maintain similar exposed surface-volume ratio than other studies that showed good balance between test duration and representativeness [11]. Steel rings were laser cut from a duplex stainless steel 2205 (EN 1.4462) seamless pipe of 3" SCH. 40s. This material was used for its high strength and resistance to local and uniform corrosion in aggressive environments. Thickness and material properties of the steel ring were chosen to obtain high degrees of restraint in order to maximize the confining stresses applied to the mortar and to avoid onset of inelastic deformations on the steel. In practice, such degrees of confinement may not be representative of the soil action, but it could be representative of other situations such as the one depicted in Figure 1.

Figure $2 \mathrm{a}$ and $2 \mathrm{~b}$ depicts a schematic representation of the molds and the casting process adopted. The molds were composed by a PE rigid base with 4 fixed PVC or steel molds with the same inner diameter and a moving PE rigid cover. The mortar (represented in light hatching) was

\section{4} poured inside the PVC or steel molds and compacted with 15 jolts in the flow table (ASTM C1437) at a rate of 1 jolt per second to eliminate air pockets. 5 bolts were used to guide the cover into the base during assembly (Figure $2 b$ ). In order to ensure adequate surface finish quality, the molds were then vibrated during 10 seconds at the vibration table. Notice that these molds allowed the casting of both free and restrained specimens by following the same procedure. By that, mortars in both configurations reached similar initial mixture properties and surface finish qualities.

Specimens were demolded 24 hours after casting. Specimens in free conditions were extracted from the PVC molds and their lateral faces were water sealed with the flexible epoxy coating MasterSeal M 338 to ensure similar penetration of the sulfate ions than in restrained specimens and to avoid corner spalling (Figure 2c). Specimens in restrained conditions were not coated 196 the specimen (Figure 2d). 

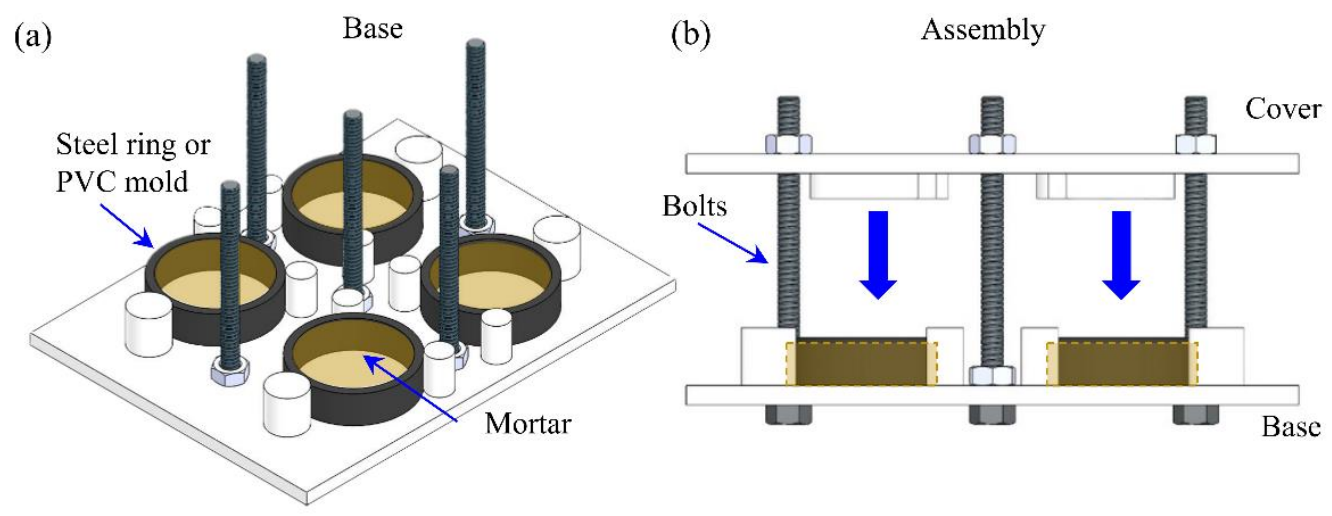

(c)

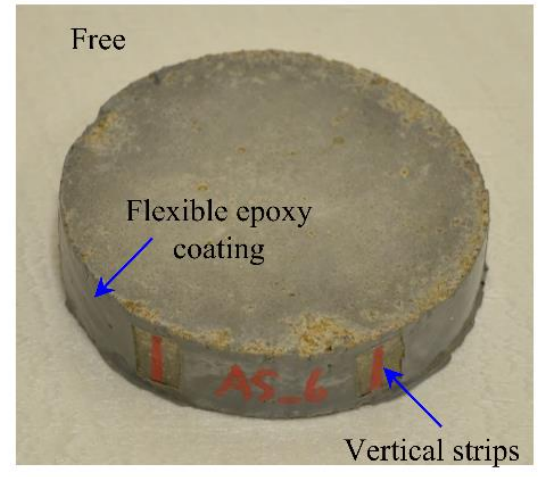

(d)

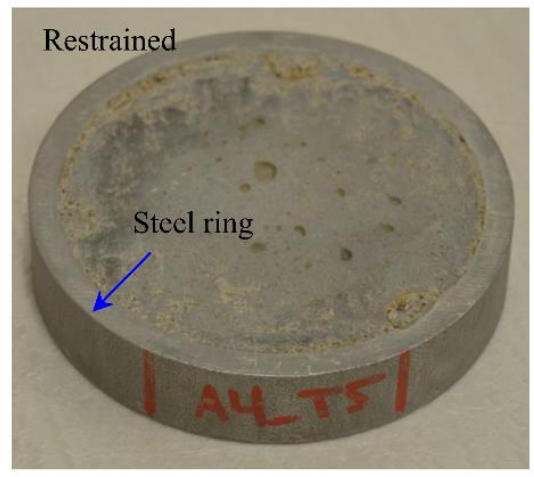

\subsubsection{EXPOSURE CONDITIONS}

All specimens were cured in water at $25^{\circ} \mathrm{C} \pm 1{ }^{\circ} \mathrm{C}$ for one day to ensure full saturation of the samples prior to sulfate exposure. Two days after casting, specimens were exposed to two different sodium sulfate solutions ( 3 and $30 \mathrm{~g}$ of $\mathrm{Na}_{2} \mathrm{SO}_{4} / \mathrm{l}$ ). The sulfate concentration of $3 \mathrm{~g} / \mathrm{l}$ corresponds to the upper limit of the moderately aggressive class of exposure defined in EN 2061 , whereas $30 \mathrm{~g} / \mathrm{l}$ corresponds to 10 times the typical values found in the field conditions [12]. The early exposure was adopted to reproduce the conditions of structures build in situ and to accelerate the attack [12]. The age of sulfate exposure is considered as day 0 in the analysis of the results. The solution was renewed weekly during the first month and every other week until the end of the test at 365 days. The volumetric ratio of sulfate solution to mortar was 12 .

Water pumps were used at low speed to ensure a continuous flow from the bottom to the top of

213 the container in order to minimize concentration gradients. The containers were filled up to the

214 top and covered to reduce contact with the air, thus limiting $\mathrm{CO}_{2}$ dissolution and carbonation.

215 Reference samples of each composition with and without confinement rings were exposed to

216 non-aggressive curing with water without sulfates for comparative purposes.

\subsubsection{TEST METHODS}


A MICROMASTER electronic micrometer with a precision of $\pm 0.001 \mathrm{~mm}$ was used to measure the expansions of free and restrained specimens (Figure 3). A metallic platform braced with the micrometer was used to fix the specimen and measured points. Several vertical strips were introduced to facilitate the measuring and to guarantee a similar position of the specimens (Figures $2 \mathrm{c}$ and $2 \mathrm{~d}$ ). Prior to the start of the experimental program, the precision of the equipment was evaluated on free and restrained specimens during a series of over 500 measurements. Both free and restrained specimens showed a variability of the measurements of $\pm 0.002 \mathrm{~mm}$. Measurements were taken weekly during the first month and every other week until the end of the study. For each specimen, 3 radial directions were measured at each time (Figure $3 \mathrm{a}$ and $3 \mathrm{~b}$ ). Since 3 replicas were considered, each expansion value presented in this study is the average of 9 measurements.

233

(a)
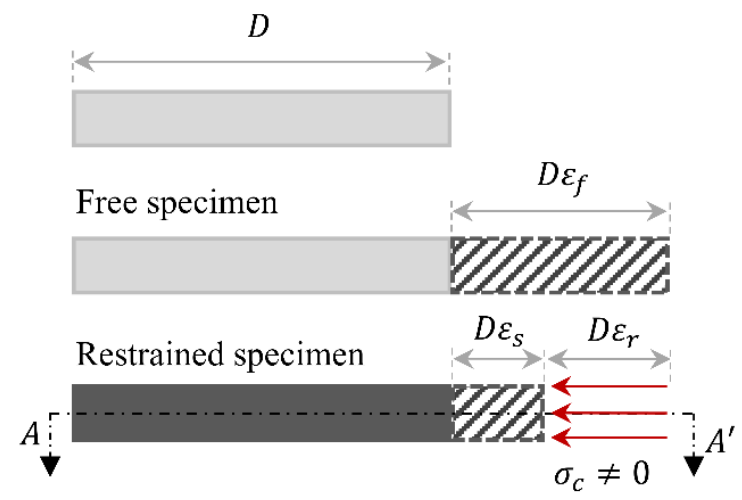

(b)

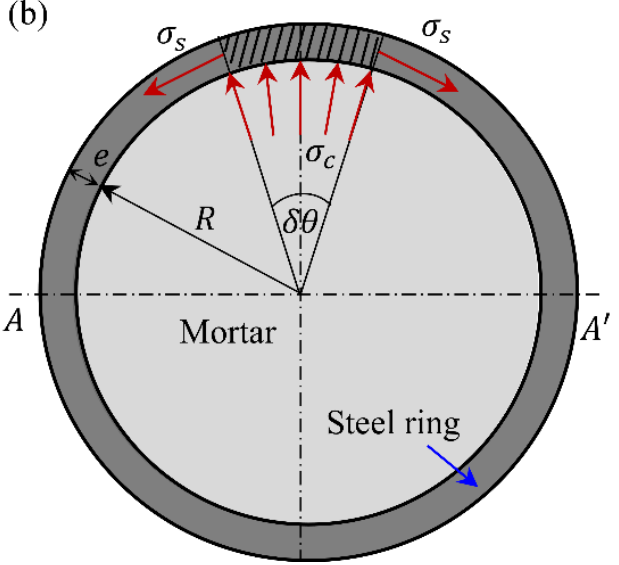

234

\section{- Macrostructural monitoring}

Characterization of the macro-scale behavior relies upon measurements of ultrasonic velocity and mass variation and visual inspection of the specimens. Ultrasonic pulse velocity between the two exposed faces was measured at $500 \mathrm{kHz}$ sampling frequency with a PUNDIT PL-200. A high frequency transducer was selected due to the low thickness of the specimens $(17 \mathrm{~mm})$. A zero-crossing algorithm was used to calculate the travelling time of the ultrasonic signal. The measurements were performed immediately after extraction from the solution tanks to ensure similar saturation conditions. A sample holder was used to fix the position of the measured location (the center of the specimen). Mass evolution was controlled with a precision balance of $\pm 0.01 \mathrm{~g}$. In this case, surface water of the samples was dried before weighting. Measurements were taken weekly during the first month and every other week until the end of the study. The values of ultrasonic pulse velocity and mass presented in this study represent the average of three specimens. 
Differences on phase composition between free and restrained specimens were investigated by XRD at 90, 180 and 365 days. Samples for XRD were core drilled from the center of the exposed faces of the original specimens using a column drill equipped with a diamond drill bit cooled with water (14 mm of diameter). For each dosage, samples were extracted from the same specimen to reduce the variability of the results. Due to the symmetric sulfate exposure conditions, each sample was divided in two. One half was crushed and the powder was pressed in cylindrical standard sample holders of $16 \mathrm{~mm}$ of diameter and $2.5 \mathrm{~mm}$ of height. The other half was discarted. XRD measurements were made using a PANalytical X'Pert PRO MPD Alpha1 $\Theta / 2 \Theta$ diffractometer in reflection Bragg Brentano geometry of $240 \mathrm{~mm}$ of radius. $\mathrm{CuK}_{\alpha 1}$ radiation $(\lambda=1.5406 \AA)$ and $X^{\prime}$ Celerator detector with active length of $2.122^{\circ}$ were used. Work power was set to $45 \mathrm{kV}-40 \mathrm{~mA}$. $\Theta / 2 \Theta$ scans from 4 to $80^{\circ} 2 \Theta$ with a step size of $0.017^{\circ} 2 \Theta$ and a measuring time of 50 seconds per step were performed. Sample holders were spun at 2 revolutions per second.

Rietveld analysis using external standard method was performed with the XRD results for the quantitative study of the crystalline phases. The external standard method was used for quantification instead of the more common internal standard method to avoid homogenisation problems and further dilution of the cement paste in the analyzed sample [13-15]. The adopted methodology is similar to earlier works [13-15]. Phase weight fractions were calculated from phase scale factors by comparison to the scale factor of the external standard $\left(\mathrm{Al}_{2} \mathrm{O}_{3}\right)$, measured under identical diffractometer conditions. The values of density and volume of the unit cell of each phase were obtained from data sets from ICSD. Mass attenuation coefficients (MAC) of the different compositions used were calculated from the MAC of each component, including the water content and considering the weight fraction of all components. Final MAC of the different mortars used are listed in Table 2.

All Rietveld refinements were done with X'Pert High Score Plus software package by PANalytical using the structures listed in Table 3. Small peaks of Fe-substituted ettringite formed as a result of the reaction between sulfate ions and the ferroaluminate phases were detected in some mortars at late stages of the attack. Since its crystalline structure for Rietveld refinement was not available it was not considered during quantification. The global variables refined were the background polynomial with 4 coefficients $\left(1^{\text {st }}, 2^{\text {nd }}, 3^{\text {rd }}\right.$ and $\left.5^{\text {th }}\right)$ and the zero shift. For all phases detected, individual scale factors and lattice parameters were refined. A pseudo-Voigt function was chosen to model the peak shape. The phase profile width $(w)$ was refined for quarz, ettringite, portlandite and gypsum. For quarz and portlandite, the profile parameters $U, V$ and the peak shape were also refined. Preferred orientation corrections were

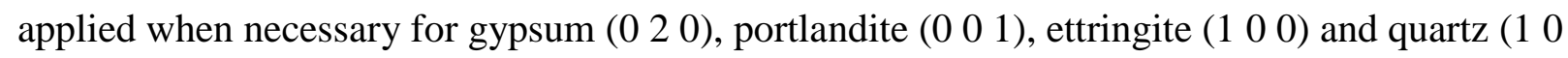
1 ) as long as the phase content was above $2 \%$. 
Table 3. Phase structures used for Rietveld refinement.

\begin{tabular}{cccc}
\hline \hline Phase & Chemical composition & $\begin{array}{c}\text { ICSD } \\
\text { Code }\end{array}$ & Reference \\
\hline Alite & $\mathrm{Ca}_{3} \mathrm{SiO}_{5}$ & 94742 & {$[16]$} \\
Belite_o & $\mathrm{Ca}_{2} \mathrm{SiO}_{4}$ & 81097 & {$[17]$} \\
Portlandite & $\mathrm{Ca}(\mathrm{OH})_{2}$ & 15471 & {$[18]$} \\
Calcite & $\mathrm{CaCO}_{3}$ & 79673 & {$[19]$} \\
Ettringite & $\mathrm{Ca}_{6} \mathrm{Al}_{2}\left(\mathrm{SO}_{4}\right)_{3}(\mathrm{OH})_{12} 26 \mathrm{H}_{2} \mathrm{O}$ & 155395 & {$[20]$} \\
Gypsum & $\mathrm{CaSO}_{4} 2 \mathrm{H}_{2} \mathrm{O}$ & 15982 & {$[21]$} \\
Ferrite & $\mathrm{Ca}_{2} \mathrm{AlFeO}_{5}$ & 9197 & {$[22]$} \\
Quartz & $\mathrm{SiO}_{2}$ & 200721 & {$[23]$} \\
Mullite & $\mathrm{Al}_{4,74} \mathrm{Si}_{1,25} \mathrm{O}_{9,63}$ & 66448 & {$[24]$} \\
Corundum & $\mathrm{Al}_{2} \mathrm{O}_{3}$ & 73725 & {$[25]$} \\
\hline \hline
\end{tabular}

296 Morphology of the hydrates precipitated during sulfate exposure at the end of the test were 297 examined by SEM (Jeol J-6510) using backscattered and secondary electrons at the voltage of 20 $298 \mathrm{kV}$. Chemical composition was determined by energy disperse X-ray spectroscopy (EDS).

299 Sections of the samples extracted were cut with an end-cutting plier perpendicular to the exposed 300 surfaces. Fractured samples were frozen in liquid nitrogen, dried in vacuum during 48 hours and 301 coated with carbon.

\subsubsection{CONFINING STRESSES PROVIDED BY THE STEEL RING}

In this work, the strain evolution measured in free and restrained specimens were used to 306 estimate the theoretical and real confining stresses generated during the attack. In free expanding 307 conditions, stresses generated by ESA are released in the form of strains. However, when the 308 strains are restrained due to the steel ring only a fraction of the stresses generated by the attack 309 are released in the form of expansions, while the other fraction confines the mortar with 310 compressive stresses $\left(\sigma_{c}\right)$. This situation is depicted in Figure 4a, where free, restrained and steel 311 expansions are denoted as $\varepsilon_{f}, \varepsilon_{r}$ and $\varepsilon_{s}$, respectively. The term D corresponds to the diameter of 312 the specimen. 


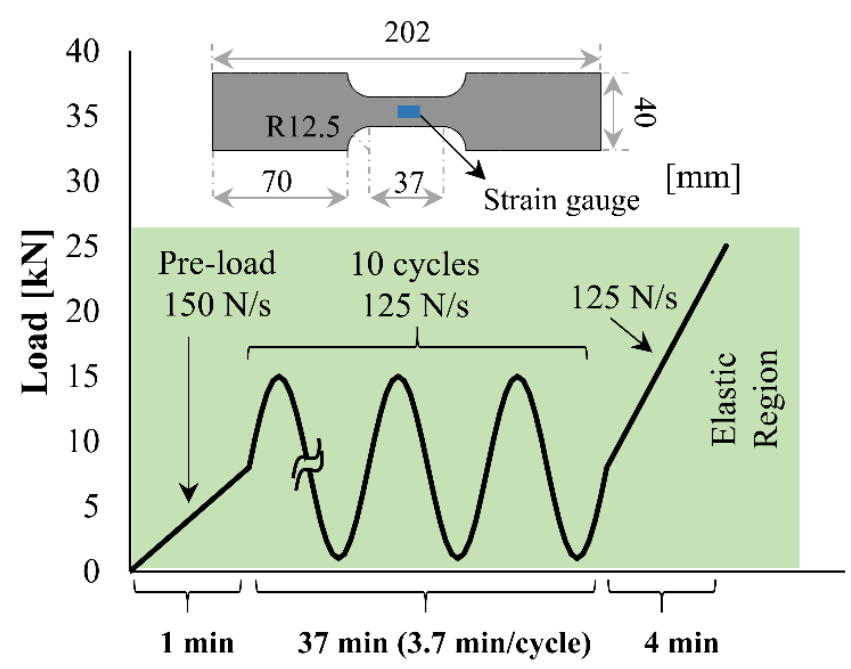

316 Figure $4 \mathrm{~b}$ shows the ideal stress distribution assumed to estimate the confining stresses $\left(\sigma_{c}\right)$. As depicted, compressive stresses are balanced by tensile stresses in the steel ring $\left(\sigma_{S}\right)$. By imposing equilibrium in the steel ring, it is possible to relate the increase of confining stresses applied to the mortar with the increment of strains measured in the steel ring between $t_{n}$ and $t_{n+1}$ (Eq. 1). In Eq. $1, E_{s}$ and $e$ refers to the elastic modulus and the thickness of the steel ring, while $R$ represents the radium of the mortar specimen (Figure 4b). Eq. 1 assumes a linear behavior of the steel, which is verified in Section 3 by the low stresses developed.

$$
\Delta \sigma_{c}\left(t_{n+1}, t_{n}\right)=\frac{\Delta \varepsilon_{s}\left(t_{n+1}, t_{n}\right) E_{s} e}{R}
$$

By introducing the strain evolution measured in confined specimens $\left(\varepsilon_{s}\right)$, Eq. 1 provides the real confining stresses developed in these samples. Additionally, the experimental set up designed measures the strain of its corresponding sample in free expanding conditions $\left(\varepsilon_{f}\right)$. To estimate the theoretical confining stresses developed for a given $\varepsilon_{f}$, it is necessary to consider the strains relation described in Eq. 2 and the constitutive law of mortar. According to Figure 4a, for any given time interval expansions generated in free specimens $\left(\varepsilon_{f}\right)$ are the sum of the expansions measured in confined specimens $\left(\varepsilon_{s}\right)$ and the ones restrained by the presence of the steel ring $\left(\varepsilon_{r}\right)$

332 (Eq. 2). Eq. 3 shows the mortar constitutive law assumed, which is described in the Spanish 333 building code EHE-08 for concrete structures. Notice that this equation takes into account the second order effects of structurally indeterminate specimens (creep and potential cracking).

$$
\Delta \varepsilon_{f}\left(t_{n+1}, t_{n}\right)=\Delta \varepsilon_{s}\left(t_{n+1}, t_{n}\right)+\Delta \varepsilon_{r}\left(t_{n+1}, t_{n}\right)
$$




$$
\begin{aligned}
\Delta \sigma_{c}\left(t_{n+1}, t_{n}\right)= & \left(\Delta \varepsilon_{r}\left(t_{n+1}, t_{n}\right)-\sum_{i=1}^{i=n-1} \frac{\Delta \sigma_{c}\left(t_{i}\right)}{E_{c, 28}}\left(\varphi_{c}\left(t_{n+1}, t_{i}\right)-\varphi_{c}\left(t_{n}, t_{i}\right)\right)\right) \\
& \cdot \frac{E_{c}\left(t_{n}\right)}{1+\frac{E_{c}\left(t_{n}\right)}{E_{c, 28}} \varphi_{c}\left(t_{n+1}, t_{n}\right)}
\end{aligned}
$$

336
In Eq. 3, the terms $E_{c}\left(t_{n}\right)$ and $E_{c, 28}$ represent the elastic modulus of mortar at a certain time and at 28 days, respectively. Potential cracking caused by high compressive stresses generated in the mortar due to the expansions restrained is considered by a degradation of the elastic modulus $\left(E_{c}\left(t_{n}\right)\right)$, initiating a plastic behavior of the material for stresses higher than $80 \%$ of the compressive strength. The effects of creep are considered in Eq. 3 by the creep coefficients $\varphi_{c}$, which are calculated according to the equations provided in the Spanish building code EHE-08. This expression is valid as long as the stresses remain below the $45 \%$ of the mortar compressive strength. The theoretical confining stresses and strains generated over time in restrained specimens are estimated from Eqs. 1, 2 and 3, considering that at $t=0$ the influence of creep and cracking is null.

Due to the importance of the Young Modulus of the steel rings for the assessment of the confining stresses generated (real and theoretical), two tensile coupon tests were performed to precisely determine this parameter. Coupon dimensions and loading configuration are depicted in Figure 5. Strain gauges were placed on each face of the coupon specimen to measure the longitudinal tensile strains. The amplitude of the cycles depicted in Figure 5 was defined to cover the expected stress levels reached during the attack. The Young Modulus $\left(E_{S}\right)$ was calculated from the slope of the strain-stress curves obtained during the 10 loading cycles. The average value obtained considering both strain gauges was $178769 \mathrm{MPa}$ with a standard deviation of $10294 \mathrm{MPa}$. 
(a)

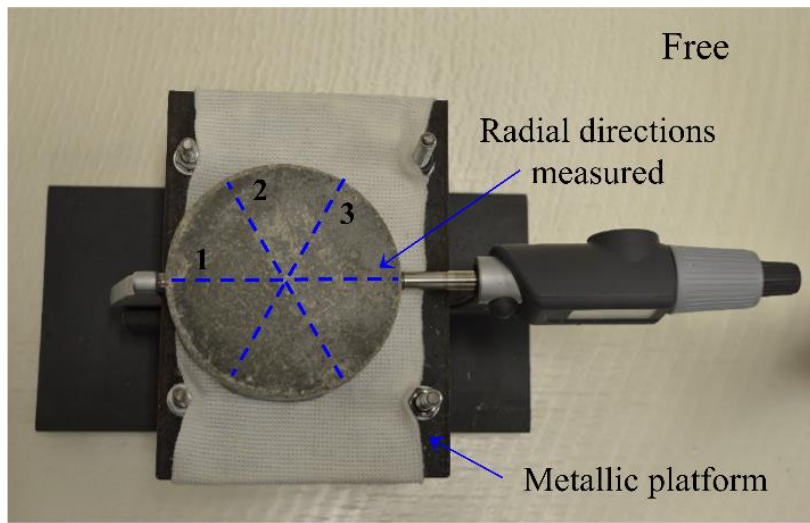

(b)

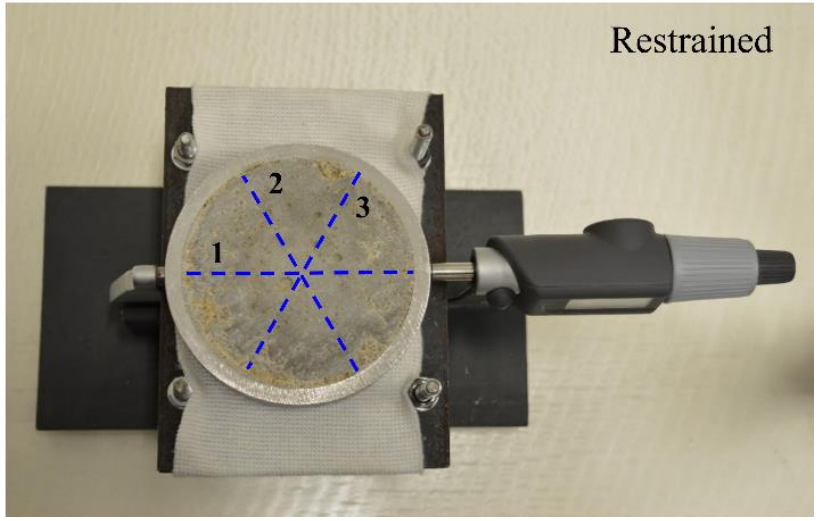

The Young Modulus of the mortar at 28 days $\left(E_{c, 28}\right)$ was indirectly estimated from ultrasonic pulse velocity measurements. The dynamic modulus of elasticity was calculated for each composition from the pulse velocity measured at 28 days according to ASTM C 597-02. Density and dynamic Poisson's ratio of $2150 \mathrm{~kg} / \mathrm{m}^{3}$ and 0.2 were assumed, respectively. The Static modulus of elasticity was estimated by considering that the dynamic modulus is 1.2 times the static modulus [26]. Values obtained for all compositions ranged between 16492 and 19595 MPa.

\section{RESULTS AND DISCUSSION}

\subsection{EXPANSIONS AND CONFINING STRESSES}

Figure 6 depicts the evolution of free and restrained expansions for specimens stored in 30 and 3 $\mathrm{g} / \mathrm{l}$. Traditionally, the expansions presented by most researchers correspond to the difference between the expansions measured in aggressive and non-aggressive conditions to isolate the effects of sulfates from dimensional variations caused by normal cement hydration processes. However, in this work expansions are used to assess the theoretical and actual confining stresses generated in the restrained specimens. For that, the discrimination of the contribution of sulfates and normal cement hydration on the expansions measured is not appropriate since all expansions contribute to generate stresses, regardless of its origin. Due to the large number of measuring 
points at each curve, $+1 /-1$ standard deviation bars are only depicted at $28,90,180,270$ and 365 days, being $3.97 \cdot 10^{-5}$ and $2.68 \cdot 10^{-5}$ the mean standard deviation for free and restrained expansion measurements, respectively. For clarity, the standard deviation bars of expansion measurements in restrained specimens are not included in Figure $6 \mathrm{~b}$ and Figure 6d. Instead, the corresponding 384 standard deviations are represented in Figure 7.

Free specimens under high aggressive conditions reach a wide variety of expansions depending on the mixture composition (Figure 6a). The expansions obtained at the end of the period assessed varies between $2.8 \cdot 10^{-3}$ and $6.6 \cdot 10^{-4}$. Mortars with fly ash and water/cement ratio of 0.55 (OPC+FA_0.45 and OPC_0.55) present the highest expansions while mortars with airentrainer and sulfate-resisting cement (OPC+AE_0.45 and SRPC_0.45) show the lowest expansions throughout the attack. On the other hand, in low aggressive curing conditions the expansions developed by free specimens presented maximum values below $5.0 \cdot 10^{-4}$ at 365 days (Figure 6c).

(a)

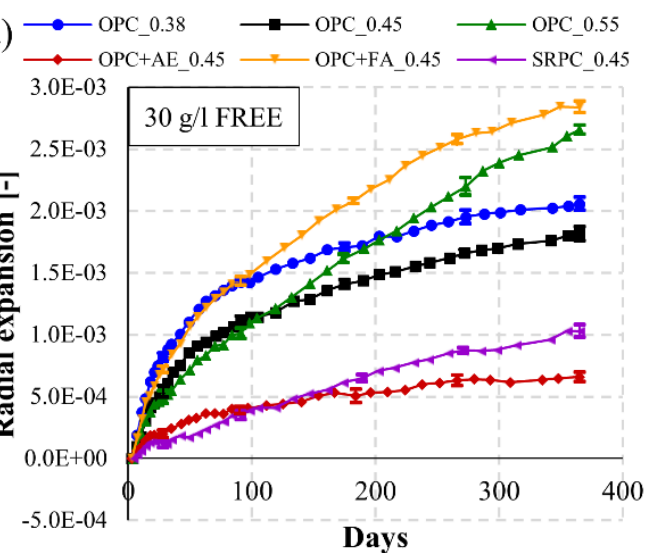

(c) $\longrightarrow$ OPC_0.38 $\longrightarrow$ OPC_0.45 $\longrightarrow$ OPC_0.55

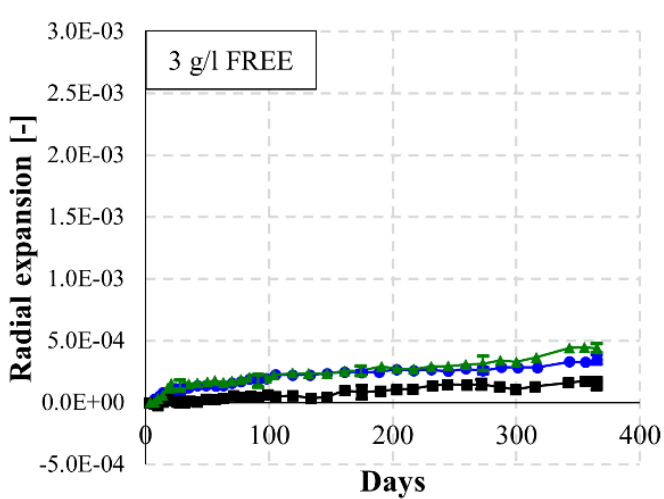

(b)
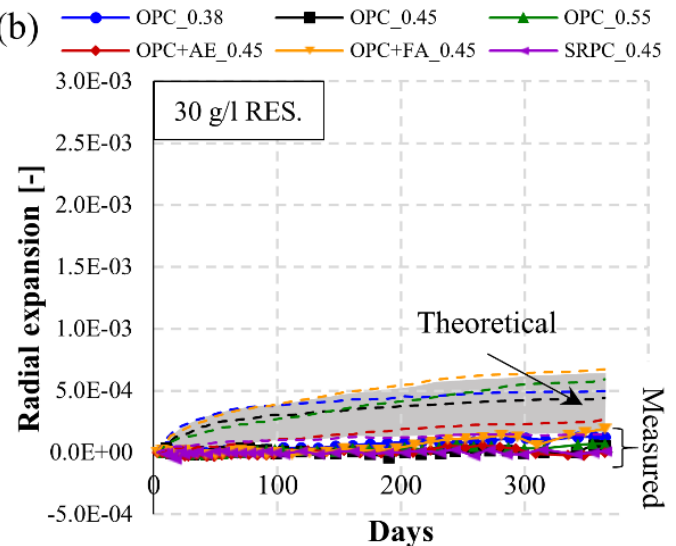

(d)

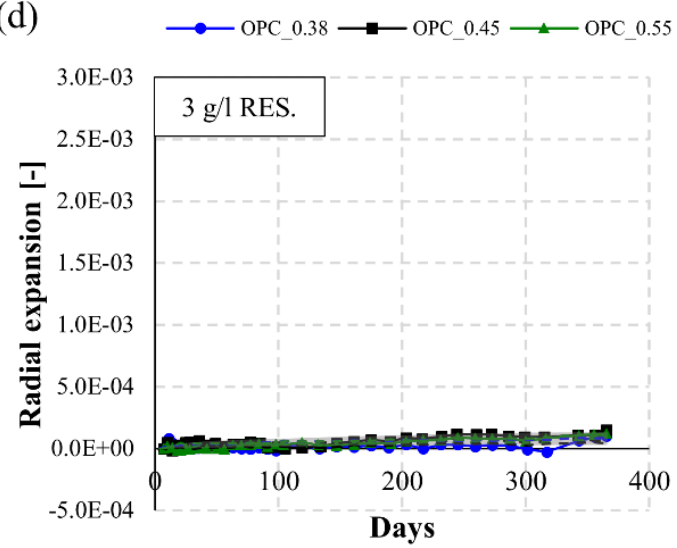
all compositions in both aggressive environments. Additionally, these figures include the 
covered by the theoretical expansions is highlighted by grey hatching. Due to the lack of experimental data, a mortar compressive strength of $40 \mathrm{MPa}$ was assumed for this calculation, which is consistent with typical values reported in the literature for this material [27]. However, a parametric analysis performed indicates that the compressive strength of the material is not a critical parameter of the model, since a $25 \%$ increase of the compressive strength only induces a 3 to $6 \%$ increase of the expansion obtained at the end of the test. As shown in Figure 6b, there is a significant difference between the theoretical and measured expansions for the high aggressive environment. Final expansions measured at 365 days are between 1.4 and 8.5 times lower than the theoretical expansions. For low aggressive conditions, measured and theoretical expansions are similar.

Figure 7 presents the real and theoretical evolution of confining stresses in restrained specimens based on the theoretical and measured expansions depicted in Figure $6 \mathrm{~b}$ and $6 \mathrm{~d}$ for high and low aggressive conditions. Real and theoretical stresses for each composition are represented with solid lines with markers and dotted lines, respectively, following the same color pattern. The envelop domain covered by the theoretical stresses is depicted in grey. Based on the mechanical contribution of the steel rings and the free expansions measured, the confining stresses applied to the restrained specimens should reach values between 3.8 and $16.8 \mathrm{MPa}$ at the end of the test in high aggressive conditions. However, as shown in Figure $7 \mathrm{a}$, the actual confining stresses generated at 365 days are significantly lower, varying between 1.9 and $4.9 \mathrm{MPa}$. As expected from Figure 6d, theoretical and actual confining stresses are similar for low aggressive conditions.

The large difference between theoretical and measured stresses are observed in all mortars. Therefore, it seems that the composition of the different matrices considered had minor effects on the confining stresses generated. Due to the low values measured, the influence of water/cement ratio, cement, air-entrainer or fly ash is not clear. In most cases, the differences
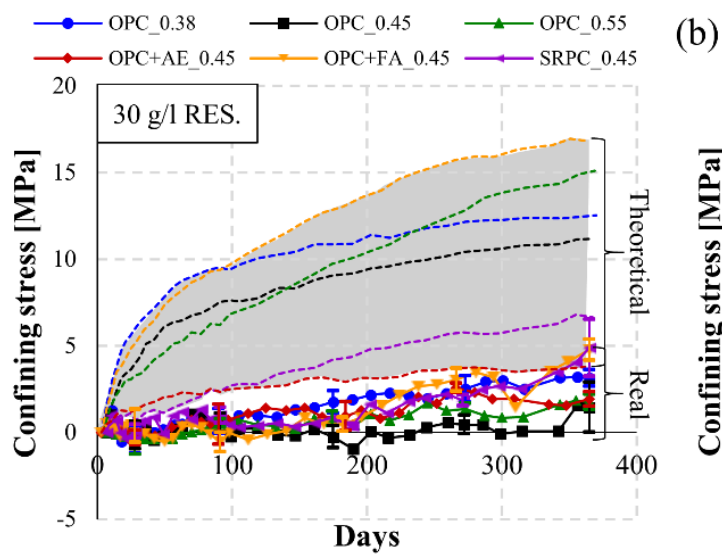

(b) $\longrightarrow$ OPC_0.38 $\longrightarrow$ OPC_0.45 $\longrightarrow$ OPC_0.55

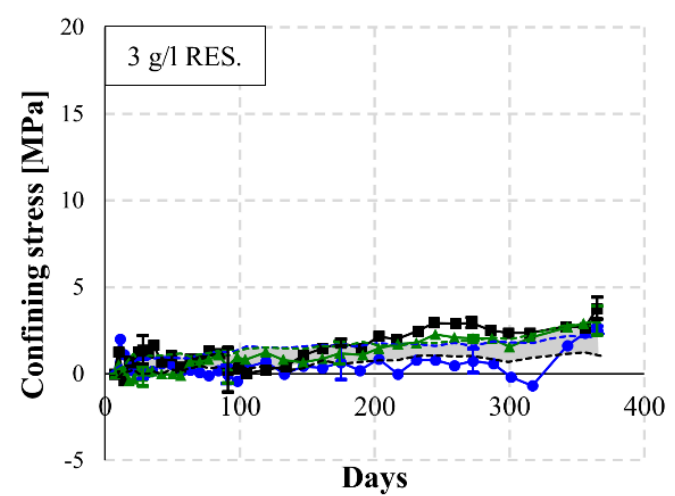
observed amongst these compositions are relatively close to the average variability of the measurements (+1/-1 mean standard deviation of $+0.67 /-0.67 \mathrm{MPa})$. 
433 These results might be partially influenced by several factors. First, the mechanical model used

434 assumes several simplifications on the consideration of the second order effects. However, for

435 the values of stresses predicted (below the $45 \%$ of the compressive strength), the model

436 described in section 2.2.4 should remain valid. On the other hand, the presence of the steel ring

437 might promote the release of strains in the non-restrained plane. Special considerations were

438 taken during the design stage of the samples to minimize this phenomenon. Due to the geometric

439 characteristics of the specimens, strains developed in the horizontal plane are about 4 times the

440 strains in the vertical plane. Therefore, it is unlikely that the large difference between the

441 theoretical and measured stresses depicted in Figure 7a is entirely explained by a transfer of

442 strains from the restrained plane to the free direction.

444 The results obtained indicate that only a small fraction of the expansions restrained by the steel

445 ring are translated into stresses. This unexpected behavior suggests the presence of an additional

446 phenomenon: There might be an interaction between the confining stresses caused by restraint

447 and processes associated with the ESA that define the expansive forces generated during the

448 attack.

\subsubsection{VISUAL ASPECT OF SAMPLES}

Figure 8 and Figure 9 allows the comparison of the external surface of free and restrained specimens for OPC+FA_0.45, OPC_0.45, SRPC_0.45 and OPC+AE_0.45 in non-aggressive conditions $(0 \mathrm{~g} / \mathrm{l})$ and high aggressive conditions $(30 \mathrm{~g} / \mathrm{l})$ at the end of the test. These mixtures are selected to cover different free expansions depicted in Figure 6a. The visual aspect of the specimens submerged in non-aggressive conditions are included here to be able to distinguish the effects of confinement on the ESA phenomenon from the normal hydration processes. Figure 8 shows no difference on the visual aspect of the external surface of free and restrained specimens 
(a)
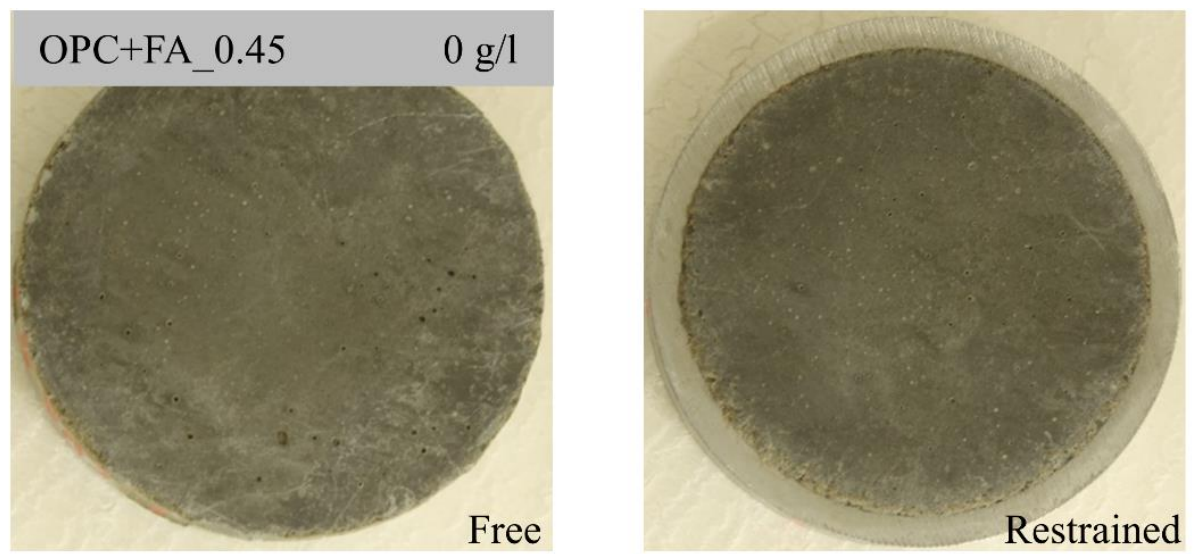

(b) OPC_0.45

(c) SRPC_0.45
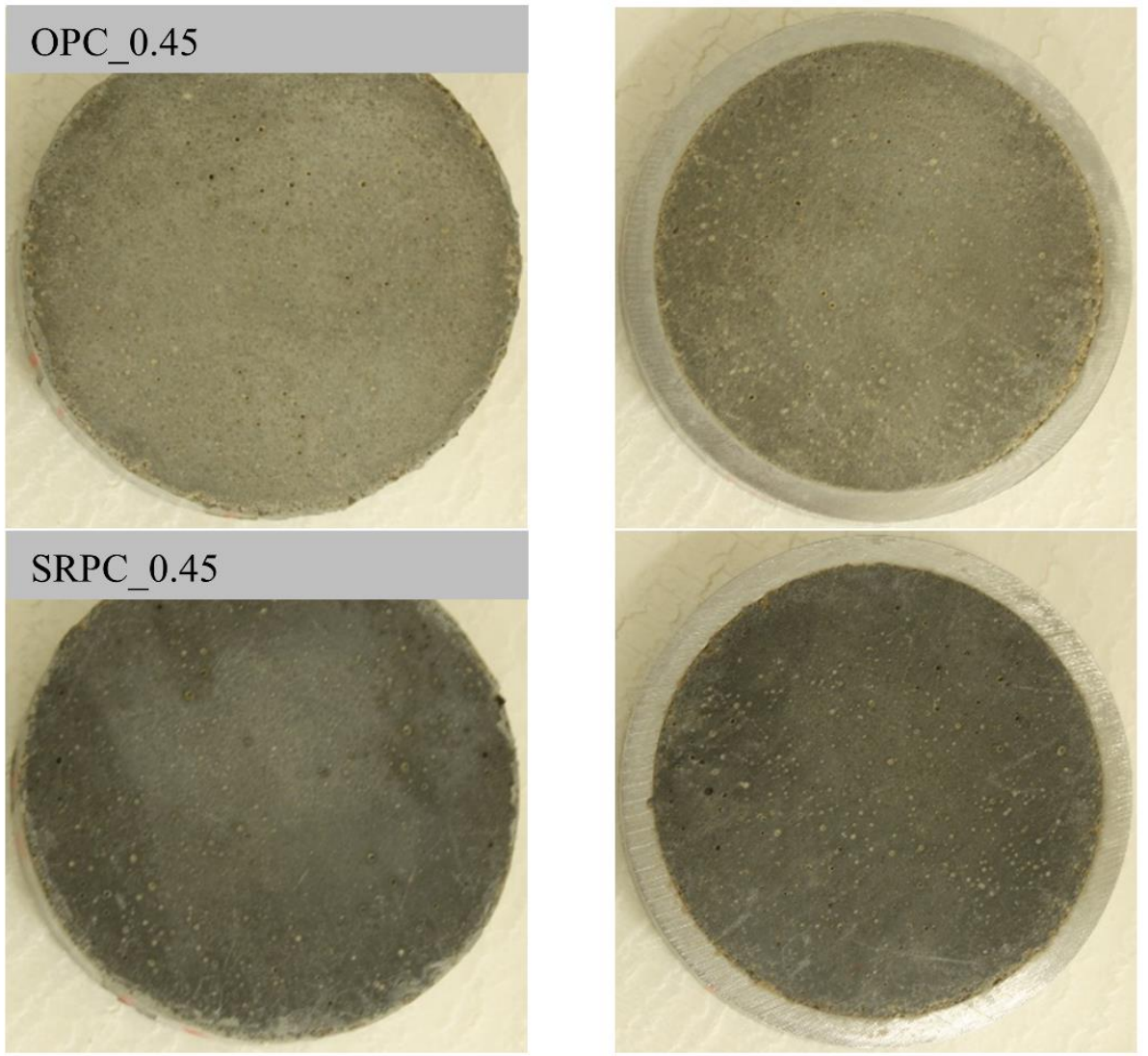

(d) $\mathrm{OPC}+\mathrm{AE} \_.45$
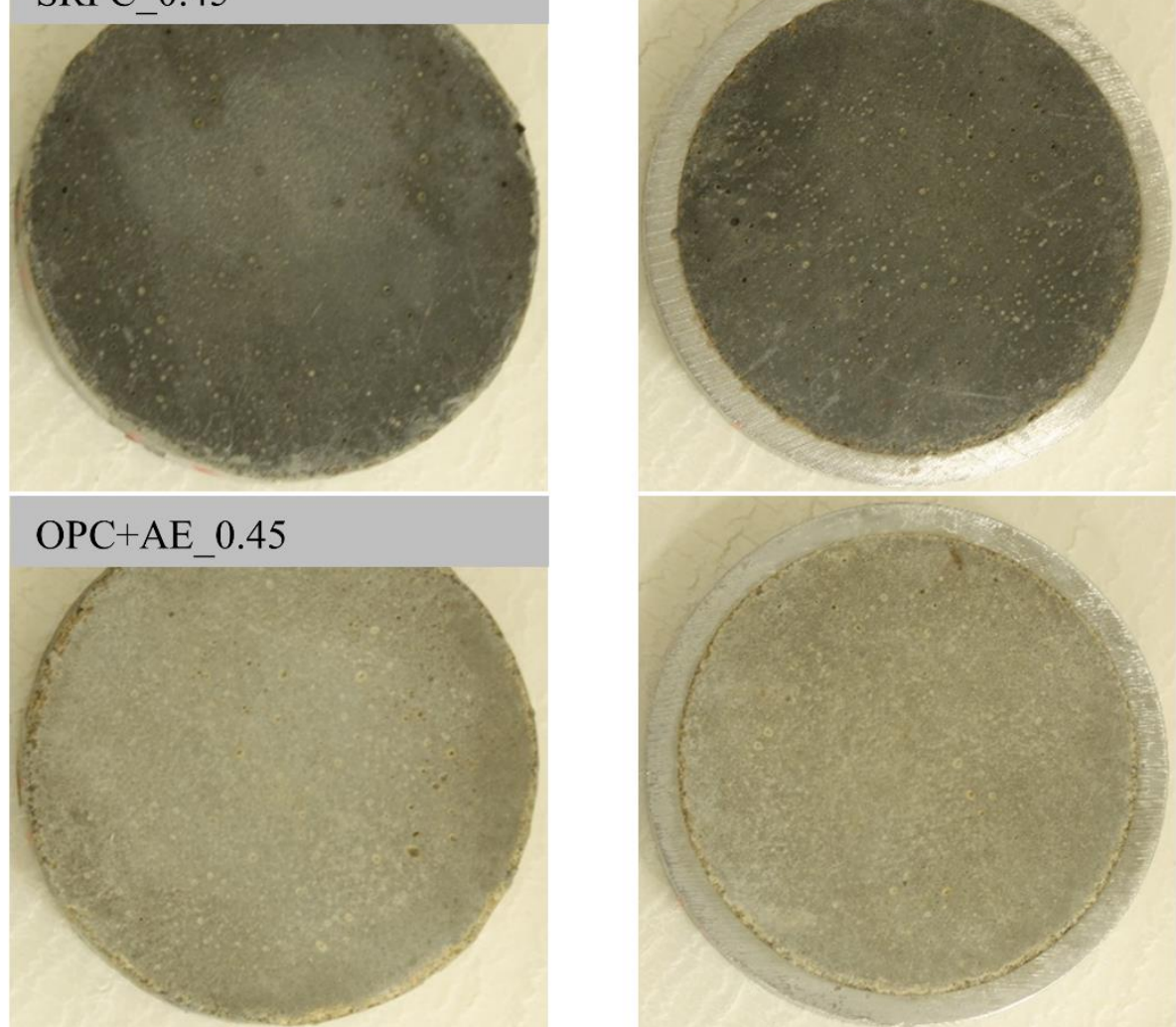
464 No major failure in the form of generalized spalling of the external surface, cracking due to

465 compressive stresses or tensile splitting is observed in any composition submerged in the 466 aggressive solution (Figure 9). Restrained and free OPC+FA_0.45 and OPC_0.45 specimens 467 present a thin dense layer covering most of the surface. In both cases, samples experienced 468 similar degrees of localized spalling (highlighted with a red circle) in locations within the region 469 covered by the dense layer. This layer is not observed in SRPC_0.45 or OPC+AE_0.45. The 470 similar visual appearance between free and restrained specimens of each composition may be 471 caused by the low confining stresses developed during the attack (below $5 \mathrm{MPa}$ ). Compressive 472 stresses of this magnitude should not cause additional damage. 
(a)

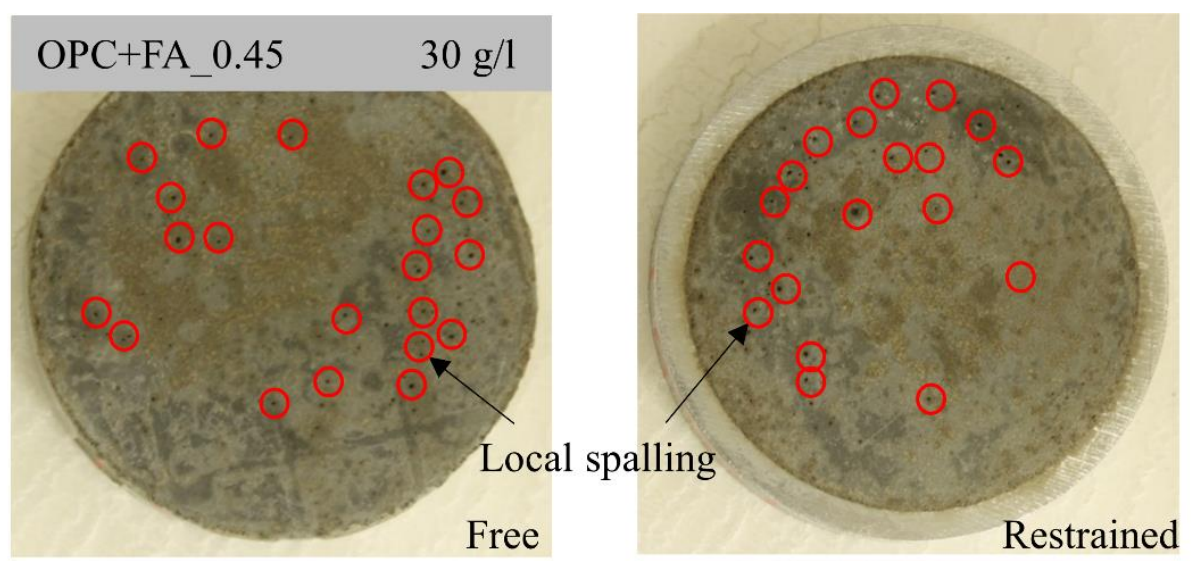

(b)

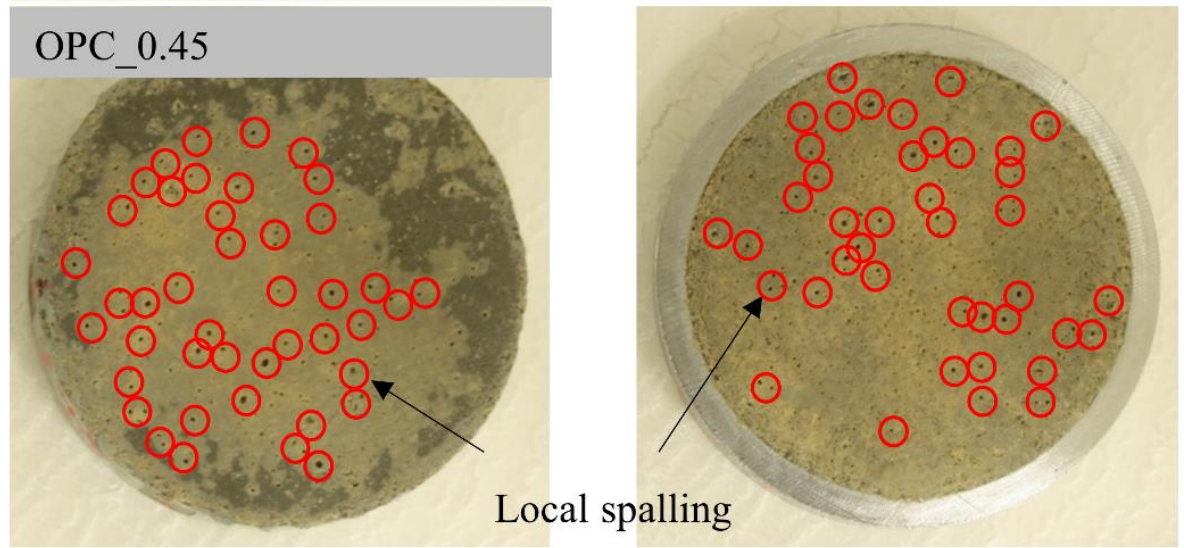

(c)

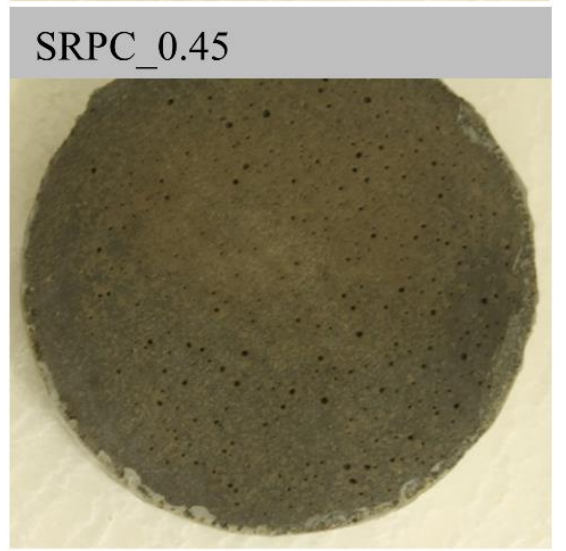

(d)
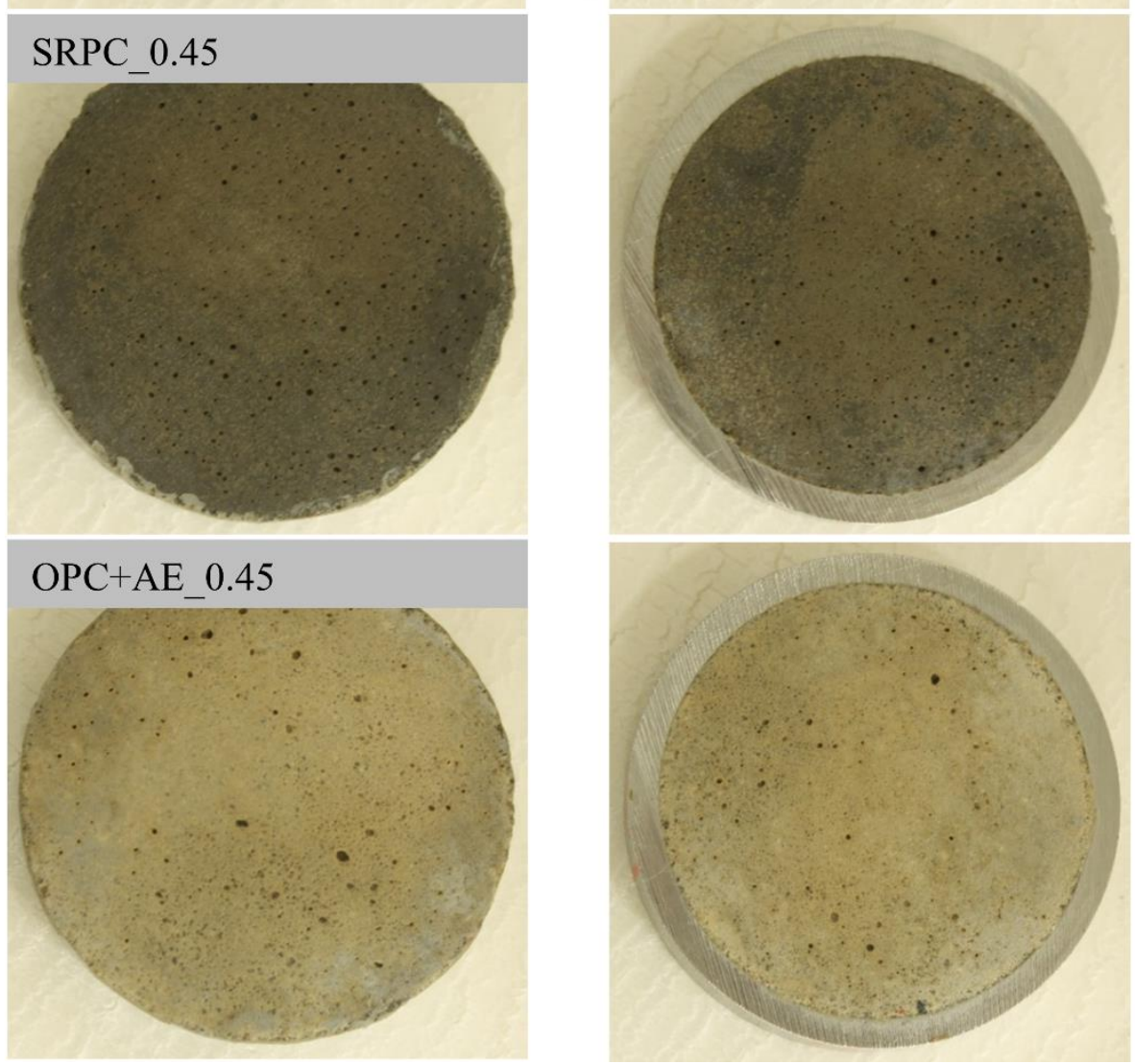
Figure 10 presents the visual aspect of OPC_0.45 in the low aggressive solution ( $3 \mathrm{~g} / \mathrm{l})$ at 365 days. As described for $30 \mathrm{~g} / \mathrm{l}$, the external surface of free and restrained mortars are in similar conditions and do not present any form of major failure. As expected, specimens show lower levels of degradation than the same composition stored in $30 \mathrm{~g} / \mathrm{l}$ (Figure 9b). Figure 10 depicts the beginning of the formation of a thin layer of precipitated product covering a small fraction of the exposed surface. At the end of the test, no local spalling is detected in any configuration.

(a)

\subsubsection{MASS VARIATION \\ 3.2.2 MASS VARIATION}
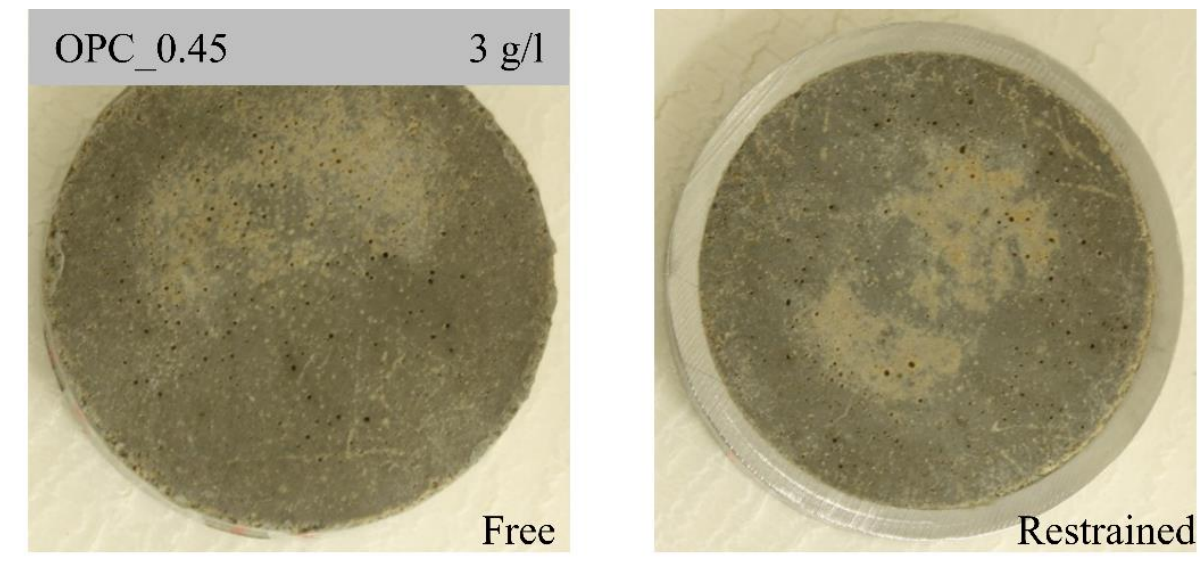

Figure 11 shows the influence of confinement on the evolution of the relative mass variation over time for all mortars stored in 30 and $3 \mathrm{~g} / \mathrm{l}$. In order to isolate the effects related to sulfate exposure from the phenomena of absorption, hydration and leaching experienced by all samples in both configurations (free and restrained), this figure represents the differences between exposed and control specimens. The relative mass variation is calculated as the ratio between the mass variation and initial mass for each composition. The envelops covered by the relative mass variation curves measured in all compositions considered for free and restrained specimens (without considering the weight of the steel ring) are represented with green and grey domains, respectively. To isolate and highlight the effects of confinement, Figure 11 includes relative mass variation curves corresponding to the difference between restrained and free specimens for each composition (represented in solid lines with markers). Curves with positive values indicate that confinement reduces the relative mass loss whereas negative values suggest that confined conditions promote mass loss. The standard deviation of the curves depicted in Figure 11 range from 0.015 to $0.021 \%$, being the $+1 /-1$ mean standard deviation of $+0.017 /-0.017 \%$.

Prior to cracking, mass variation in saturated conditions can be related to the mobility of ions between the pore and the external solution. On one hand, mortars exposed to ESA might experience positive mass changes caused by sulfate uptake from the external solution. On the other hand, negative mass changes are associated to leaching. The domains depicted in Figure 11 depict negative relative mass variations for free and restrained specimens during sulfate 
exposure. These results indicate that leaching overrides the sulfate uptake phenomenon in both aggressive conditions evaluated.

The curves corresponding to the difference between relative mass variation of restrained and free specimens shows positive values for most compositions. Based on the assumption of full saturation and the similar cracking state between free and restrained mortars (Figure 9 and 10), these results indicate lower leaching rates in confined specimens. This phenomenon might be explained by the mechanical action of the steel rings over the mortar sample. Confinement could potentially limit the appearance of micro-cracks and partially close or reduce pore channels connecting the inner layers of the matrix with the external media. Consequently, the ionic movement between the pore and external solution is indirectly reduced. This observation is in agreement with several studies that report that low or moderate compressive stresses reduce the availability of sulfates [1-3,9].

(a)

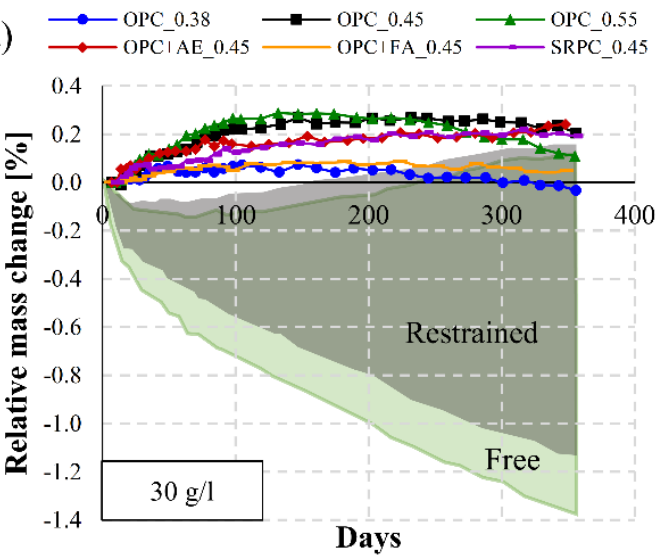

(b)

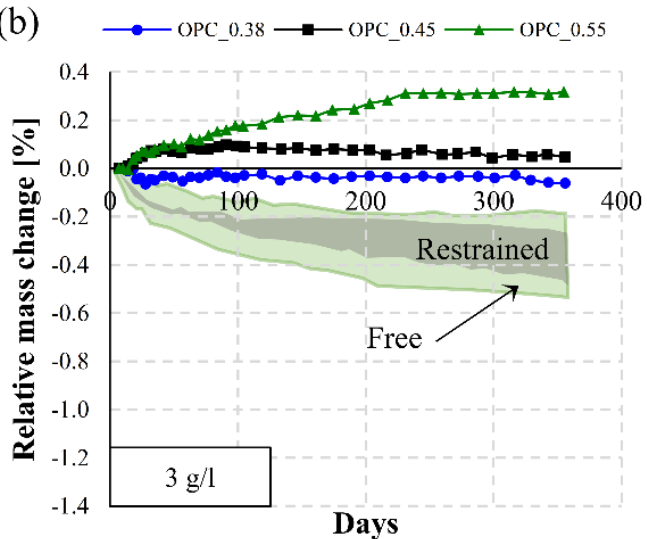

522

523

524

525

526

527

528

529

530

531

532

533

534

535

536

537
Mortars OPC_0.55, OPC_0.45, SRPC_0.45 and OPC+AE_0.45 show the highest influence of restrained conditions on the mass variation. The restrained configuration of these compositions presents on average between 2.6 to 6 times less mass reduction than mortars OPC_0.38 and OPC+FA_0.45 throughout the attack. According to these results, the lower ionic movement between internal and external solutions in restrained conditions is more significant in matrices with high water/cement ratios and the presence of air bubbles. This trend can be explained by the expectedly higher ionic flux between internal and external solutions present in those matrices due to a coarser pore network.

\subsubsection{ULTRASONIC VELOCITY VARIATION}

Figure 12 depicts the effects of expansion restraint on the ultrasonic velocity for the different compositions stored in 30 and $3 \mathrm{~g} / \mathrm{l}$. In order to isolate the effects related to sulfate exposure from the phenomena of hydration experienced by all samples in both configurations (free and restrained), the results presented in this section correspond to the differences between exposed 
and control specimens. The relative velocity change corresponds to the ratio between the velocity variation and initial velocity. The envelops covered by the measurements of relative ultrasonic velocity change in all compositions for free and restrained specimens are represented with green and grey domains, respectively. To facilitate the analysis, the effects of confinement are isolated in Figure 12 by including the relative velocity variation curves corresponding to the difference between restrained and free specimens for each composition (solid lines with markers). The standard deviation of these curves range from 1.01 to $1.45 \%$, being the $+1 /-1$ mean standard deviation of $+1.31 /-1.31 \%$.

For high aggressive conditions (Figure 12a), shaded regions depict negative relative velocity changes for free and restrained specimens. The decrease on the ultrasonic velocity indicates that ESA has caused physical damage (micro-cracks) in both configurations since the beginning of the test. Domains depicted in low aggressive conditions (Figure 12a) show either null or slightly positive velocity variations throughout the attack. These results suggest that ESA did not generate significant physical damage to the matrices in this exposure condition.

Most curves that illustrate the effects of confinement depict positive variations of ultrasonic velocity. In this case, positive values indicate that confinement causes denser matrices and lower levels of physical damage relative to the specimens in free-expanding conditions. The series OPC_0.38 and OPC_0.45 describe the most significant reduction of damage caused by confinement in high aggressive conditions (Figure 12a). For these compositions, restrained conditions prevented almost completely the formation of physical damage. The effects of confinement for the other compositions are less clear, with differences ranging from -2 to $+2 \%$. For low aggressive conditions, the 3 series evaluated present slight positive values, suggesting that confinement also causes denser matrices. However, taking into account the relatively high standard deviation of these measurements, the trends depicted in Figure $12 \mathrm{~b}$ are not sufficiently significant to sustain this statement.

$$
\text { (a) }
$$

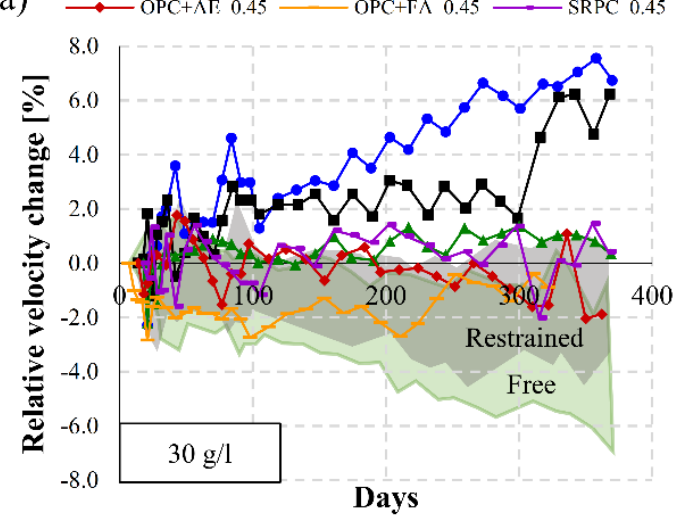

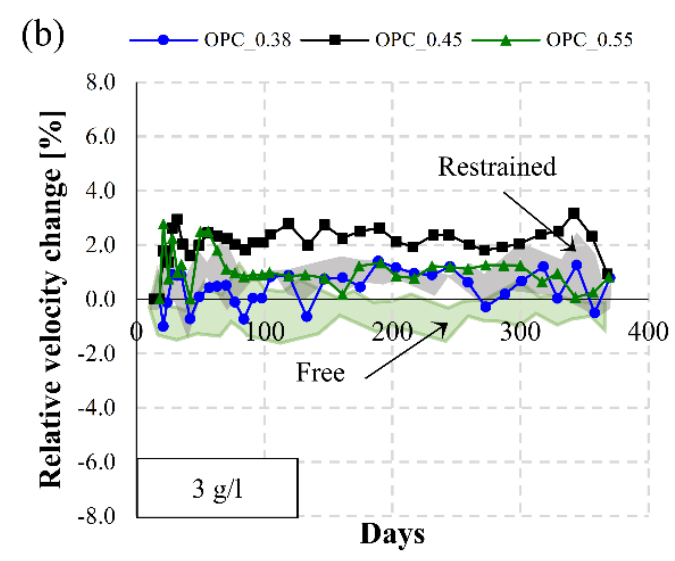


The higher integrity and density of confined matrices can be explained by the confining stresses generated by the steel rings. The compressive stresses acting in the opposite direction of the expansive forces caused by the ESA should reduce or delay the appearance of micro-cracks in the matrix. As a consequence, sulfate ingress in confined specimens might be slower than in free specimens (as suggested in section 3.2.2). A limited sulfate availability in the pore solution should cause a decrease on the amount of expansive phases precipitated and thus, reduce the damage generated. This hypothesis is verified in section 3.3.1. by the quantification of the expansive phases in free and restrained specimens.

\subsection{MICROSTRUCTURAL EFFECTS OF EXPANSION RESTRAINT}

\subsubsection{X-RAY DIFFRACTION}

This section presents a comprehensive analysis of the evolution of phase composition for free and restrained specimens by quantitative XRD. To simplify the interpretation of the results, only the main crystalline phases interacting with the sulfate ions are presented. Phase contents are expressed as a percentage of the cement content defined by the initial dosage of each composition.

Figure 13 shows ettringite, gypsum and portlandite contents for all compositions submerged in the high aggressive solution $(30 \mathrm{~g} / \mathrm{l})$ at 365 days. Values corresponding to free and restrained conditions are represented as circles and triangles, respectively. Ettringite and gypsum contents vary between 11-19\% and 3-11\%, respectively. Higher ettringite over gypsum contents were expected due to the lower solubility of ettringite [28]. The composition with the least amount of expansive phases correspond to OPC_0.38, followed by the mortar with sulfate-resisting cement. Increasing amounts of expansive phases are measured for the compositions OPC_0.55 and $\mathrm{OPC}+\mathrm{AE} \_0.45$. These trends might be explained by an increase of sulfate availability in the pore solution caused by the increase of water/cement ratio and the presence of air bubbles. Portlandite contents evolve similarly to ettringite contents. In this case, the increase of water/cement ratio and the presence of air bubbles seems to promote hydration of the silicate phases. The only composition that does not follow this trend is OPC+FA_0.45, which presents the lowest portlandite content amongst all mortars evaluated. This result can be explained by the pozzolanic activity of the fly ash, which consumes reactive silica and calcium hydroxide, producing calcium silicate hydrate [29].

\section{The differences on phase content between restrained and free specimens are presented in} clustered columns for each composition. Positive values indicate that restrained conditions promote phase precipitation while negative values suggest that the confining stresses from the steel ring hinder its formation. For most compositions, expansion restraint causes a slight decrease on ettringite content. The reduction seems to increase with the amount of ettringite 
measured in free conditions. Series $\mathrm{OPC}+\mathrm{AE} \_0.45$ presents the highest influence, with a relative decrease of $22 \%$ between free and restrained specimens. These results might be explained by the reduced mobility of ions between external and internal solutions in restrained conditions. As described in section 3.2.2, the decrease of ionic mobility and sulfate availability is more significant in compositions with high water/cement ratio and air-entrainer, which is consistent with the XRD results presented here. The effects of confinement on gypsum formation is unclear as confinement causes significant variations on gypsum content without any recognizable

615 pattern.

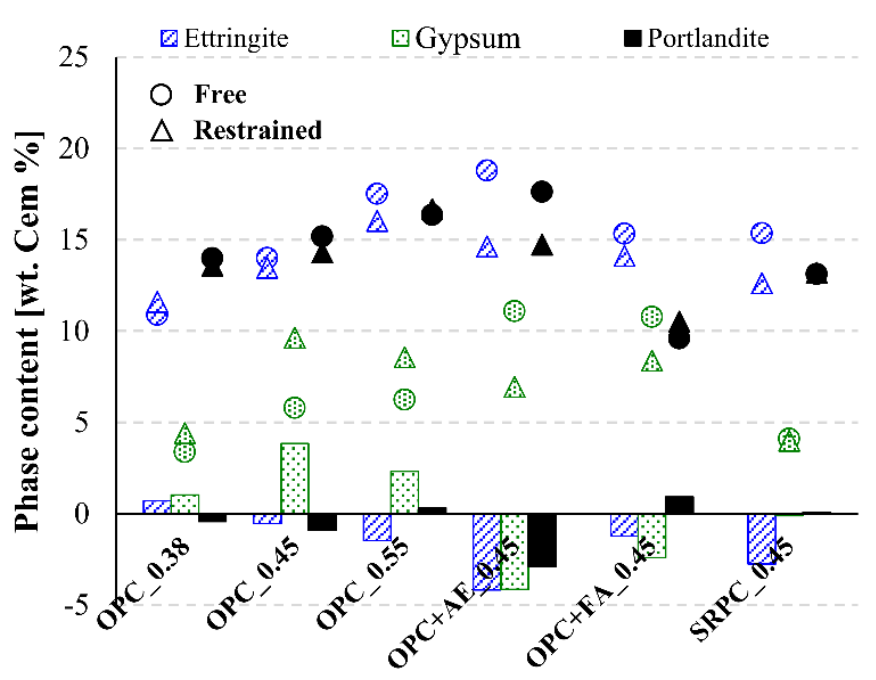

Phase composition analysis at different ages are performed to investigate the effects of confinement throughout the attack. Figure 14 shows the evolution of ettringite, gypsum and portlandite content for free and restrained OPC_0.45, OPC+AE_0.45, SRPC_0.45 and OPC_FA samples stored in $30 \mathrm{~g} / \mathrm{l}$ at 90, 180 and 365 days. These mixtures are selected to cover different magnitudes of free expansions (Figure 6a). Rietveld quantification reveals only slight variations on the total phase content within each composition from 90 days of exposure. Even though the amount of ettringite remains approximately constant, ultrasonic velocity measurements indicate that physical damage increases with time. This could suggest that the amount of ettringite is not an accurate indicator of the damage generated. Instead, the increasing levels of damage measured might be explained by variations in the location of the precipitation promoted by the continuous refinement of the pore network [30].

The phase contents depicted with clustered columns in Figure 14 (difference between restrained and free specimens) indicate that confined conditions cause a progressive reduction on the amount of expansive phases over time for series OPC+AE_0.45, SRPC_0.45 and OPC+FA_0.45. The composition OPC_0.45 do not follow the same trend due to an unexpected increase on the gypsum content at 180 and 365 days in restrained condition. 
(c)

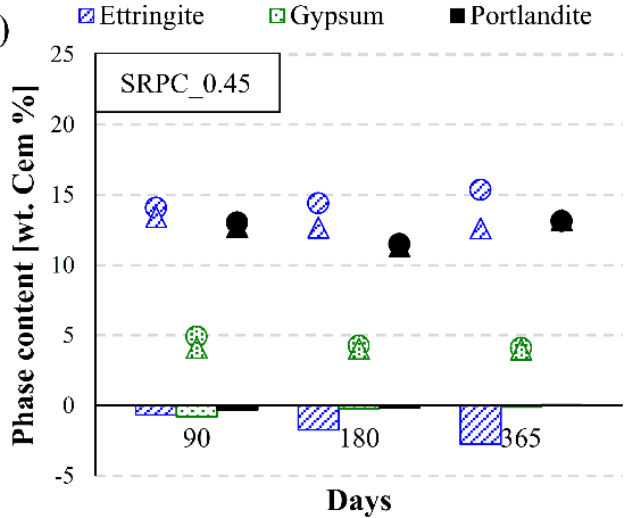

Days (a)

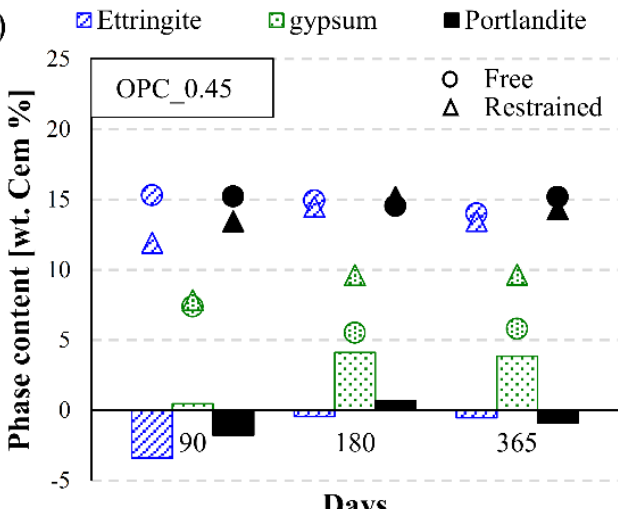

Days

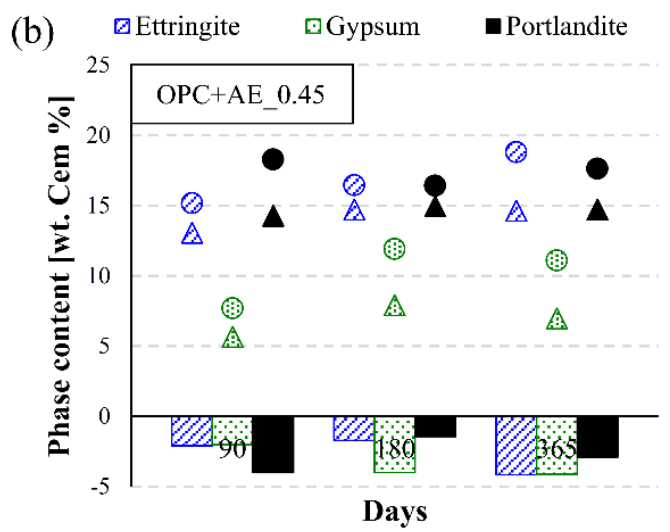

(d)

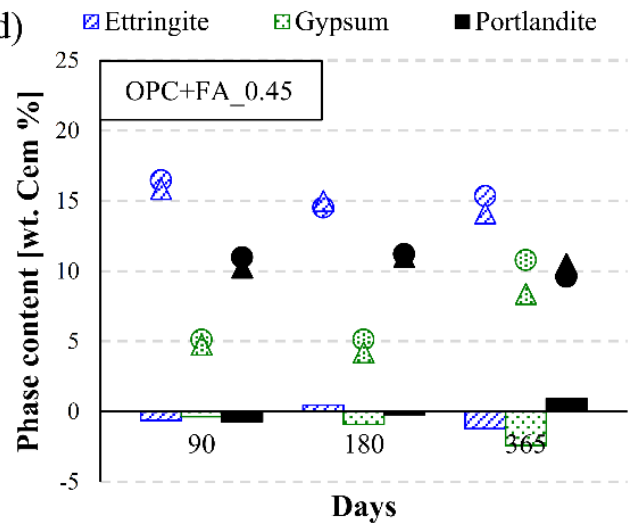

Figure 15a shows ettringite, gypsum and portlandite contents for all compositions stored in low aggressive conditions $(3 \mathrm{~g} / \mathrm{l})$ at 365 days. The phase content of all phases increases with the water/cement ratio of the composition. However, in this case the amount of expansive phases is considerably reduced due to the lower external sulfate concentration. By lowering the sulfate concentration from $30 \mathrm{~g} / \mathrm{l}$ to $3 \mathrm{~g} / \mathrm{l}$, the average ettringite contents are reduced by 8.1 and $19.2 \%$ in free and restrained specimens, respectively. In the case of gypsum, this reduction increases to 36.6 and $48.4 \%$ for free and restrained specimens. The clustered columns indicate that confinement causes a significant reduction of the ettringite content for the series OPC_0.55. However, the other compositions do not show any clear trend, with slight positive and negative variations of the ettringite and gypsum contents. Figure $15 \mathrm{~b}$ illustrates the evolution of phase composition at 90, 180 and 365 days for series OPC_0.45 stored in $3 \mathrm{~g} / \mathrm{l}$. Similarly to the results obtained for this composition in $30 \mathrm{~g} / \mathrm{l}$, absolute values of phase content remain approximately constant since 90 days of exposure and the results do not show any clear trend regarding the 

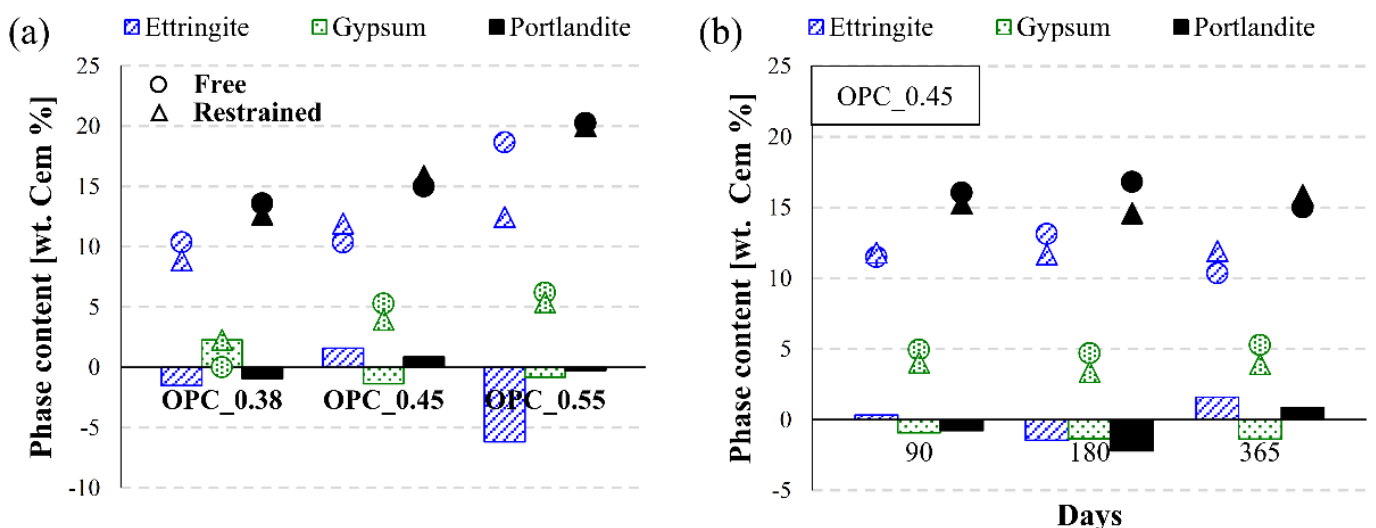

656 In general, XRD results indicate that expansion restraint causes a reduction on the amount of ettringite in most of the compositions evaluated. This reduction is more significant in the mortars with high water/cement ratio and air-entrainer (OPC_0.55 and OPC+AE_0.45). However, this trend is unclear for the compositions with lower water/cement ratios (OPC_0.38 and OPC_0.45). Notice that both OPC_0.38 and OPC_0.45 showed the highest influence of confinement according to ultrasonic velocity measurements at $30 \mathrm{~g} / \mathrm{l}$ (section 3.2.3). For these series, the presence of confining stresses caused a significant increase of ultrasonic velocity and a reduction of physical damage. This behavior was initially attributed to a limited sulfate availability and a lower precipitation of expansive phases in confined conditions. However, the results obtained in this section indicate that the lower damage measured cannot be attributed to a lower precipitation of ettringite and gypsum. Therefore, results suggest that there might be an additional phenomenon acting in restrained specimens that causes the lower levels of deterioration observed.

Free and restrained samples of mortar compositions OPC+AE_0.45, OPC_0.55 and OPC_0.38 submerged in the high aggressive solution $(30 \mathrm{~g} / \mathrm{l})$ were evaluated at 365 days. The regions analyzed by EDS are indicated by a red circle in the corresponding image. The relative intensities of each element calculated from the counting are placed on the upper right corner. The peaks considered to measure the intensity of $\mathrm{Ca}, \mathrm{Si}, \mathrm{S}$ and $\mathrm{Al}$ correspond to the energies of 3.73, $1.78,2.33$ and $1.52 \mathrm{keV}$, respectively.

Figure 16 shows the microstructure of porous regions observed in OPC+AE_0.45 for free and restrained configurations. In free expanding conditions, a significant fraction of the visible pores is partially or completely filled with large needle-like ettringite crystals (Figure 16a). The length of those crystals is approximately $10 \mu \mathrm{m}$. In restrained conditions, the majority of pores are not filled with any large crystalline structure, giving the appearance of emptiness. However, most pores present a thin layer of poorly crystalline phases covering the pore walls (Figure 16b). EDS 

crystals are spread over the pore walls instead of growing into larger structures.

(a) FREE

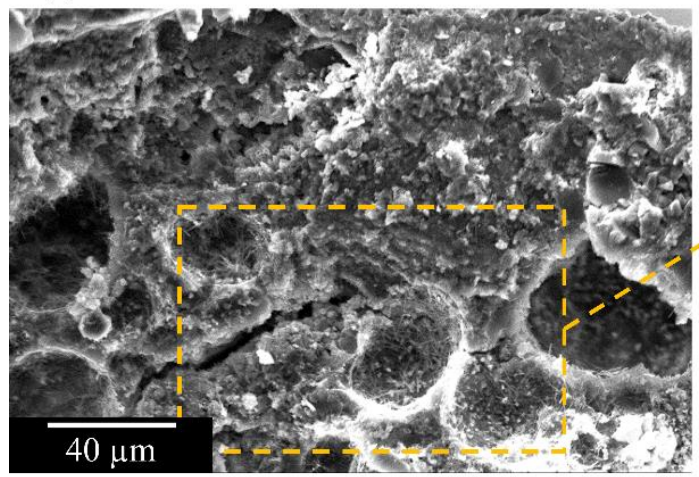

(b) RESTRAINED

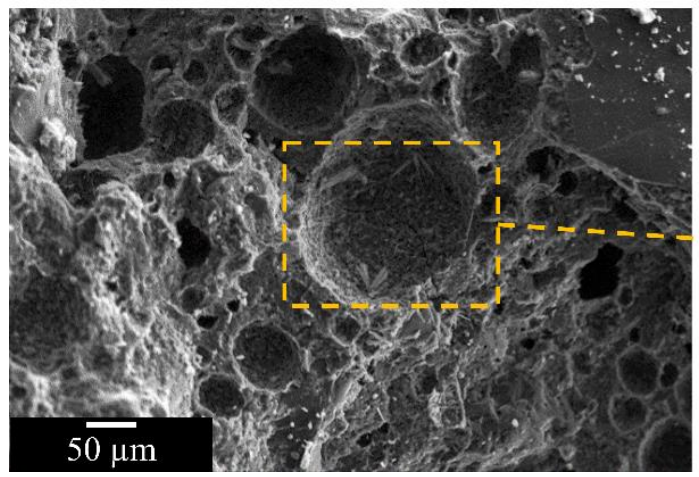

a5.4Ca:2Si:1.2S:Al

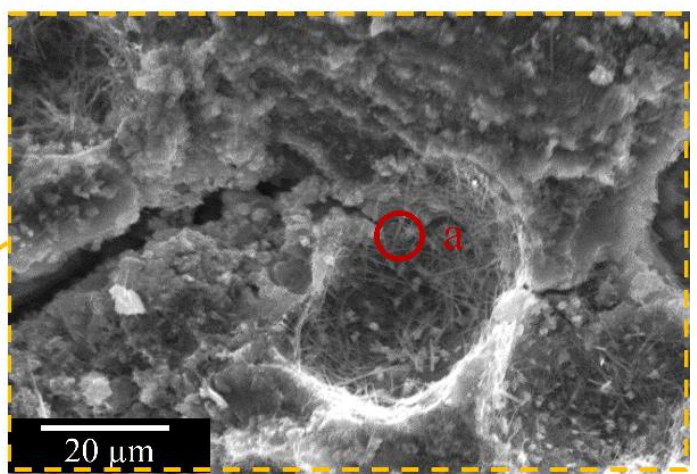

b12.8Ca:4.9Si:1.1S:A1

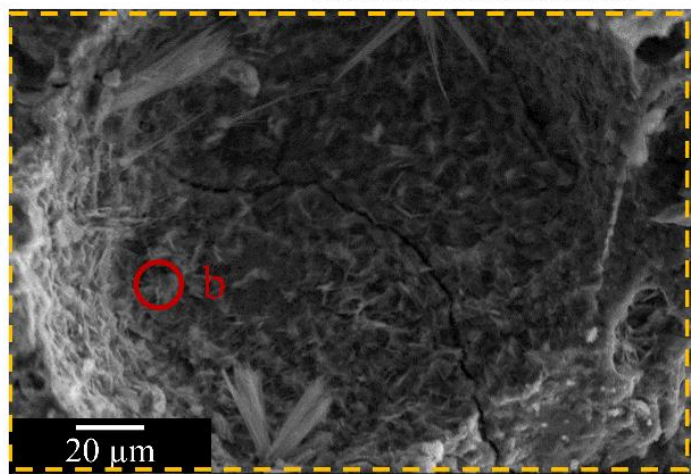

690 A comparison between the microstructure of free and restrained OPC_0.55 samples also reveals 691 significant differences on the morphology of the crystals formed (Figure 17). In free conditions, 692 large portlandite plates and ettringite clusters are easily observed inside pores (Figures 17a and 693 16b). The arrangement of these phases suggest a simultaneous growth, probably due to the early 694 age when specimens were exposed to sulfates. However, such crystalline formations are not 695 observed in restrained conditions. In this configuration, pores are either empty or filled with a 696 highly amorphous phase covering the pore walls (Figures 17c and 17d). EDS analysis performed 697 in this phase identify mostly calcium. Large ettringite crystals were not found. Highly dispersed 698 needle-like crystals were found mixed with the CSH gel in some regions outside the pores. EDS 699 detected the presence of $\mathrm{S}$ and $\mathrm{Al}$ at these locations, which might suggest that ettringite is 700 precipitating within the $\mathrm{CSH}$ gel. 


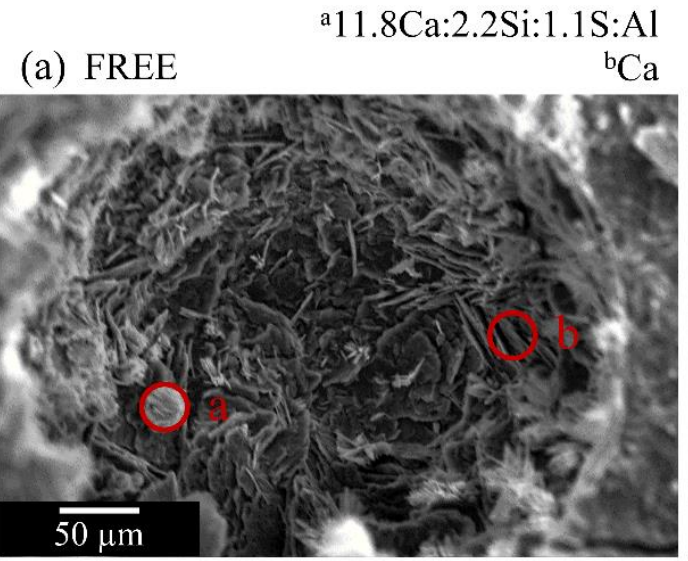

(c) RESTRAINED

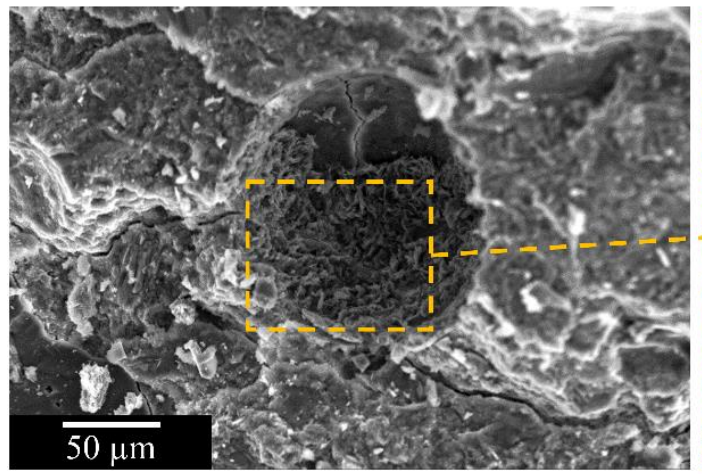

(d) RESTRAINED (b) FREE

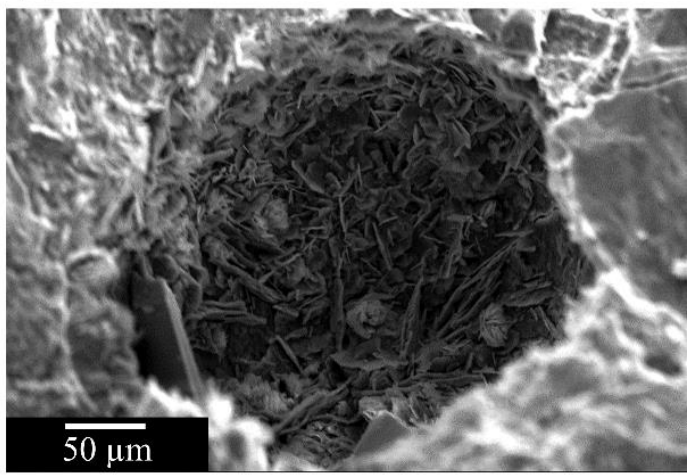

${ }^{\mathrm{c}} \mathrm{Ca}$

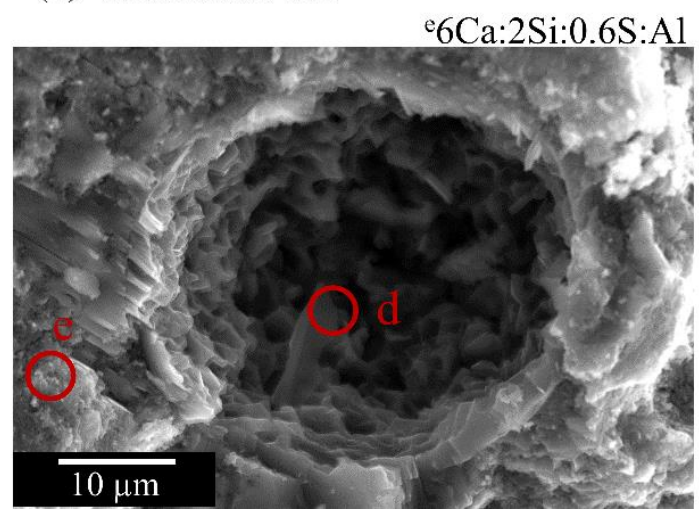

704 Similar trends are observed in the composition with lower water/cement ratio (OPC_0.38).

705 Figures 18a and 18b show large amounts of ettringite and portlandite covering the pore walls of

706 the samples in free expanding conditions. As observed in OPC_0.55, both phases present well-

707 defined structures and seem to be growing simultaneously (Figure 18b). For this composition,

708 some pores with similar hydration products were also found in restrained conditions (Figure

709 18c). However, a magnification of the crystals covering the pore walls depicts smaller structures

710 with lower degrees of crystallinity than the ones observed in free conditions (Figure 18b). 
(a) FREE

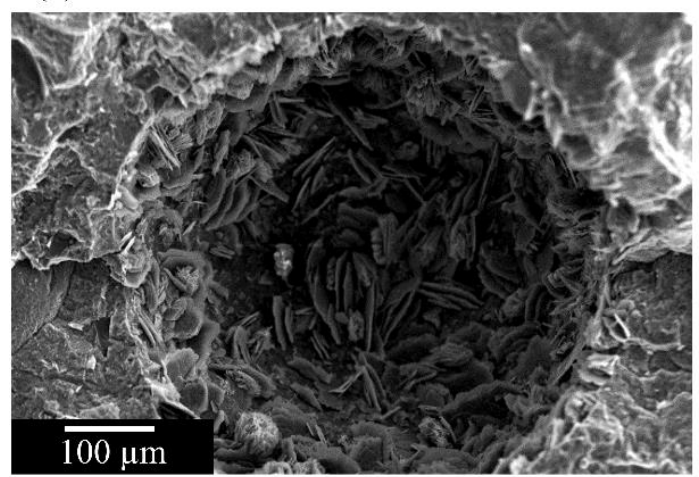

(c) RESTRAINED

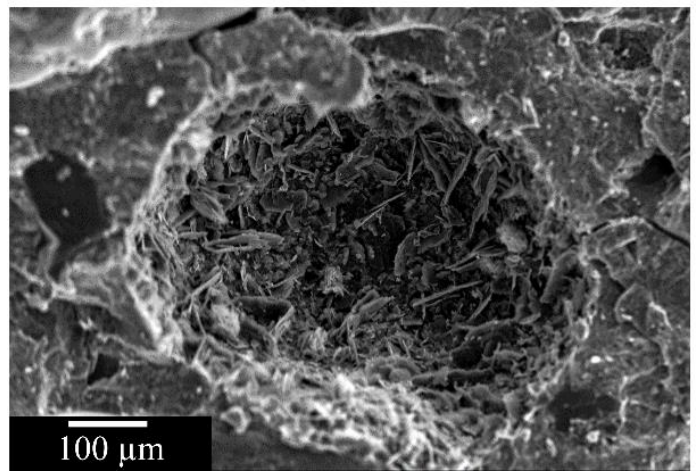

(b) FREE

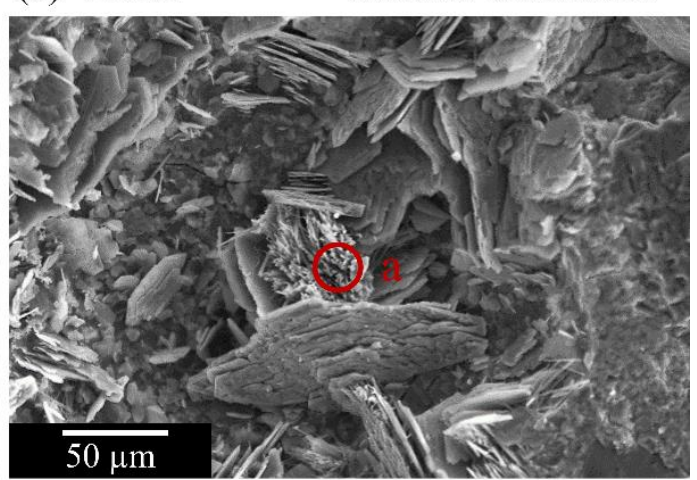

(d) RESTRAINED

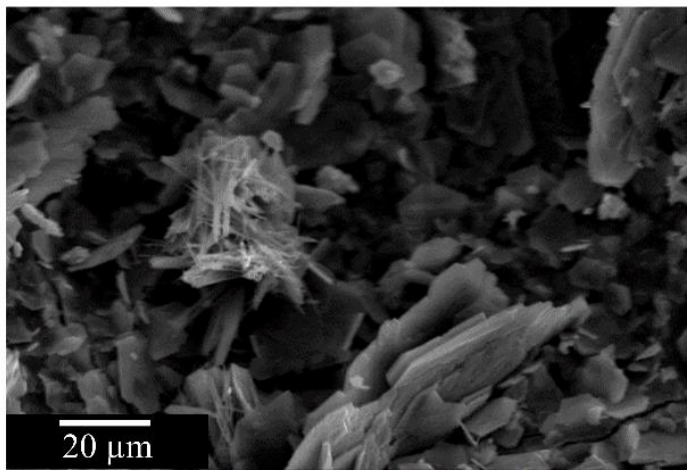

\subsubsection{DISCUSSION OF SEM RESULTS}

716 Results of the SEM analysis suggest that size and degree of crystallinity of phases formed during

717 ESA might be affected by expansion restraint. In the same way a structure element deforms after

718 the application of an external stress, when a crystal is subjected to stresses it might change its

719 dimensional configuration by precipitation and dissolution mechanisms until equilibrium is

720 reached with the surrounding media. Some authors studied different aspects related to the effects

721 of pressure on crystal growth caused by salt crystallization between pore walls [31-34]. The

722 theoretical framework developed by M. Steiger [32,33] is used here to assess the influence of

723 externally generated confining stresses due to expansion restraint on crystal development.

725 When a crystal grows in directions in which growth is opposed by external forces, free and

726 loaded faces of the crystal present different values of chemical potential. According to [35], the

727 chemical potential of a crystal face under pressure $p\left(\mu_{p}\right)$ can be expressed as indicated in Eq. 5

728 when elastic behavior is assumed. The contribution of the molar strain energy of a deformed

729 crystal is neglected since the pressure difference between free and confined specimens is below

$730100 \mathrm{MPa}[32,35]$.

$$
\mu_{p}=\mu_{0}+p V_{m}
$$


In this equation, $\mu_{0}$ is the chemical potential of the solid in the unstressed reference state and $V_{m}$ is the molar volume of the solid in the stressed state. This equation shows that the loaded faces of a crystal have higher chemical potentials than unloaded faces. On the other hand, the chemical potential of the salt in the solution $\left(\mu_{l}\right)$ increases with the ion activity of the solute $(K)$ in the pore solution (Eq. 6). The term $\mu_{l}^{0}$ refers to the chemical potential in the standard state.

$$
\mu_{l}=\mu_{l}^{0}+R T \ln (K)
$$

739

740

741

742

743

744

745

746

747

748

749

750

751

752

753

754

755

756

757

758

759

760

761

762

763

764

765

766
Both loaded and unloaded faces of a crystal seek equilibrium with the surrounding pore solution. Therefore, as indicated in Eq. 7, the chemical potential of the solute must be equal to the chemical potential of the respective crystal face.

$$
\mu_{0}+p V_{m}=\mu_{l}^{0}+R T \ln (K)
$$

Eq. 7 shows that when a pressure is introduced to the crystal, the solubility of that crystal increases to balance the increase on chemical potential produced by the pressure. This phenomenon is sometimes referred to as "Riecke's principle". It states that the crystal solubility increases with the pressure applied. According to this principle and assuming that the pressure caused by the steel rings is transferred to the crystals growing in confined conditions, crystals formed in restrained samples should exhibit higher solubility than those in free expanding conditions. If the pressure is anisotropic, the dissolved material may then be redeposited on those parts of the crystal exposed to lower pressures. This phenomenon should cause crystals with smaller sizes and lower degrees of crystallinity in restrained specimens.

However, as indicated in section 3.1, the confining stresses generated by the steel rings are below $5 \mathrm{MPa}$. Such low stresses may not be able to cause significant effects on the solubility of the phases precipitated, as stresses in the order of $20 \mathrm{MPa}$ are necessary to increase $20 \%$ the solubility of $\mathrm{NaCl}$ crystals at $25^{\circ} \mathrm{C}$ [32]. According to M. Steiger [32], the increase of solubility due to an increase of pressure $(\Delta p)$ can be estimated by Eq. 8 . In this equation, the term $K_{0}$ corresponds to the ion activity product of the saturated solution.

$$
\ln \left(\frac{K}{K_{0}}\right)=\frac{\Delta p V_{m}}{R T}
$$

Figure 19 presents the equilibrium curve of the solubility increase produced by pressures between $0-5 \mathrm{MPa}$ in ettringite, gypsum and portlandite crystals at $25^{\circ} \mathrm{C}$. The molar volumes considered for those phases are 707, 75 and $33 \mathrm{~cm}^{3} / \mathrm{mol}$, respectively [28]. Ettringite depicts a significant increase of solubility within the pressures evaluated. The solubility at $5 \mathrm{MPa}$ of 
pressure is 4.2 times the reference solubility in the absence of load, which indicates that ettringite is very sensitive to the range of pressures applied. This phenomenon could promote a decrease of large ettringite crystals in restrained conditions. For the other phases considered, the influence of stresses up to $5 \mathrm{MPa}$ on the solubility is minimum.

772 The high supersaturation needed to counteract the effects of pressure might alter the balance 773 between crystal growth and nucleation rate around the ettringite crystals growing in confined

774 conditions. According to [36], the rate of nucleation (I) can be expressed as indicated in Eq. 9.

775 This equation has been simplified by grouping all the parameters other than supersaturation into

776 the positive coefficients $\mathrm{A}$ and $\mathrm{B}$. Large $\mathrm{K} / \mathrm{K}_{0}$ leads to rapid nucleation of ettringite. Therefore, a 777 local increase of solubility might promote ettringite nucleation over crystal growth in those

778 regions where ettringite is mainly growing in confined conditions, ultimately resulting in smaller crystals distributed over a large surface.

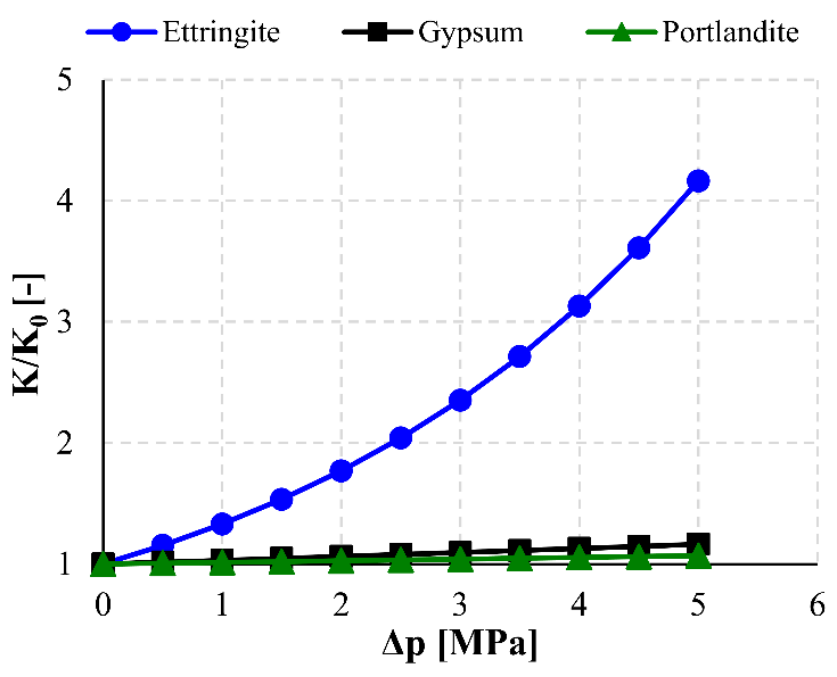

784 The crystallization pressure theory states that the crystals must be confined in order to exert pressure. Therefore, the expansive stress generated in a specimen depends on the volume fraction of crystals growing in confined conditions [34]. The smaller crystal size distribution of ettringite caused by its increased solubility in the restrained specimens might reduce the fraction of crystals growing in confined conditions and thus, the amount of crystals exerting pressure. This phenomenon, together with the lower presence of ettringite, could explain the low confining stresses measured and the reduced damage observed in specimens under restrained conditions.

791 However, further experimental research is needed to link the theoretical framework developed 792 here and the trends described by the SEM images of section 3.3.2, as it was not possible to 
compare images of ettringite crystals growing in confined conditions for free and restrained

794 specimens.

\section{CONCLUSIONS}

The results presented in this paper indicate that the confining stresses alter the normal development of the ESA by reducing the potential damage generated. The following specific conclusions may be derived from this study. is significantly smaller than the stresses predicted considering the free expansions of equivalent unconfined samples. Such difference confirms the important role of the confinement in the outcome of the attack and raises questions about the representativeness of the accelerated laboratory tests conducted under unconfined conditions. The numerical simulation of the structural repercussion of the ESA obtained by applying free expansion in structural models should also be questioned since it is likely to bring higher stresses than expected in reality in case confinement exists.

(2)- Results of mass variation suggest that the ionic transport process between external and pore solutions is reduced in confined conditions. This behavior might be explained by the lower micro-cracking generated, which decreases the penetration paths and reduces the sulfate

(3)- The evolution of the ultrasonic velocity confirms that confined specimens present denser matrices and lower presence of micro-cracks than equivalent unconfined specimens.

(4)- In general, XRD results indicate that the confinement causes a reduction on the amount of expansive phases precipitated, especially in compositions with high water/cement ratios and airentrainer. The lower precipitation observed might be explained by the reduced availability of sulfates in confined conditions.

(5)- The theoretical framework formulated to explain the effects of confinement on the morphology and arrangement of the crystals formed suggests that confinement might increase the solubility of ettringite and promote a spread nucleation of small crystals in those regions where ettringite growth is restrained. These phenomena might reduce the amount of crystals growing in confined conditions and thus generating pressure, which may contribute to explain the lower stresses generated by the attack in the confined specimens. Further experimental evidences are needed to validate this hypothesis.

832 ACKNOWLEDGMENTS 
Support from the Spanish Ministry of Economy and Competitiveness through research project BIA2013-49106-C2-1-R is greatly acknowledged. T. Ikumi is supported by the fellowship program FPI BES-2014-068524 of the Spanish Ministry of Economy and Competitiveness.

\section{REFERENCES}

[1] W. Piasta, Z. Sawicz, J. Piasta, Sulfate durability of concretes under constant sustained load, Cem. Concr. Res. 19 (1989) 216-227.

842 [2] U. Schneider, W. Piasta, The behaviour of concrete under $\mathrm{Na}_{2} \mathrm{SO}_{4}$ solution attack and 843 sustained compression or bending, Mag. Concr. Res. 43 (157) (1991) 281-289.

844 [3] V. Zivica, V. Szabo, The behavior of cement composite under compression load at sulphate attack, Cem. Concr. Res. 24 (8) (1994) 1475-1484.

846 [4] K. Werner, Y. Chen, I. Odler, Investigations on stress corrosion of hardened cement pastes, Cem. Concr. Res. 30 (2000) 1443-1451.

848 [5] M.T. Bassuoni, M.L. Nehdi, Durability of self-consolidating concrete to sulfate attack under combined cyclic environments and flexural loading, Cem. Concr. Res. 39 (2009) 206-226. [6] D. Yang, J. Luo, The damage of concrete under flexural loading and salt solution, Constr. Build. Mater. 36 (2012) 129-134.

852 [7] R. Gao, Q. Li, S. Zhao, Concrete Deterioration Mechanisms under Combined Sulfate 853 Attack and Flexural Loading, J. Mater. Civ. Eng. 25 (1) (2013) 39-44.

854 [8] J. Gao, Z. Yu, L. Song, T. Wang, S. Wei, Durability of concrete exposed to sulfate attack under flexural loading and drying-wetting cycles, Constr. Build. Mater. 39 (2013) 33-38. [9] H. Xu, Y. Zhao, L. Cui, B. Xu, Sulphate attack resistance of high-performance concrete under compressive loading, J Zhejiang Univ-Sci A (Appl Phys \& Eng) 14 (7) (2013) 459-468. [10] W. Müllauer, R.E. Beddoe, D. Heinz, Sulfate attack expansion mechanisms, Cem. Concr. 859 Res. 52 (2013) 208-215.

860 [11] R. El-Hachem, E. Rozière, F. Grondin, A. Loukili, New procedure to investigate external sulphate attack on cementitious materials, Cem. Concr. Compos. 34 (2012) 357-364.

862 [12] A. Chabrelie, Mechanisms of degradation of concrete by external sulfate ions under 863 laboratory and field conditions, PhD Thesis, ÉPFL, Lausanne, 2010.

864 [13] D. Jansen, F. Goetz-Neunhoeffer, C. Stabler, J. Neubauer, A remastered external standard 865 method applied to the quantification of early OPC hydration, Cem. Concr. Res. 41 (2011) 602866608.

867 [14] D. Jansen, C. Stabler, F. Goetz-Neunhoeffer, S. Dittrich, J. Neubauer, Does Ordinary 868 Portland Cement contain amorphous phase? A quantitative study using an external standard 869 method, Powder Diffract. 26 (2011) 31-38.

870 [15] R. Snellings, A. Bazzoni, K. Scrivener, The existence of amorphous phase in Portland 871 cements: Physical factors affecting Rietveld quantitative phase analysis, Cem. Concr. Res. 59 872 (2014) 139-146. 
873 [16] A.G. de la Torre, S. Bruque, J. Campo, M.A.G. Aranda, The superstructure of $\mathrm{C}_{3} \mathrm{~S}$ from 874 synchrotron and neutron powder diffraction and its role in quantitative analysis, Cem. Conc. Res. $87532(2002) 1347-1356$.

876 [17] W.G. Mumme, R.J. Hill, G.W. Bushnell, E.R. Segnite, Rietveld crystal structure 877 refinements, crystal chemistry and calculated powder diffraction data for the polymorphs of 878 dicalcium silicate and related phases, N. Jb. Miner. Abh. (J. Min. Geochem.) 169 (1995) 35-68. 879 [18] H.E. Petch, The hydrogen positions in portlandite, $\mathrm{Ca}(\mathrm{OH}) 2$, as indicated by the electron 880 distribution, Acta Crystallogr. 14 (1961) 950-957.

881 [19] R. Wartchow, Datensammlung nach der "learnt profile"-methode(LP) für calcit und 882 vergleich mit der "background peak background"-methode (BPB), Z. Kristallogr. 186 (1989) 883 300-302.

884 [20] F. Goetz-Neunhoeffer, J. Neubauer, Refined ettringite structure for quantitative X-ray 885 diffraction analysis, Powder Diffr. 21 (2006) 4-11.

886 [21] W.A. Wooster, On the crystal structure of gypsum CaSO4(H2O)2, Z. Kristallogr. 94 887 (1936) 375-396.

888 [22] A.A. Colville, S. Geller, The crystal structure of brownmillerite, Ca2FeAlO5, Acta 889 Crystallogr. B 27 (1971) 2311-2315.

890 [23] L. Levien, C.T. Prewitt, D.J. Weidner, Structure and elastic properties of quarz at 891 pressure, Am. Mineral. 65 (1980) 920-930.

892 [24] T. Ban, K. Okada, Structure refinement of mullite by the Rietveld method and a new 893 method for estimation of chemical composition, J. Am. Ceram. Soc. 75 (1992) 227-230.

894 [25] E.N. Maslen, V.A. Streltsov, N.R. Streltsova, N. Ishizawa, Y. Satow, Synchrotron X-ray 895 study of the electron density in alpha-Al2O3, Acta Crystallogr. B 49 (1993) 973-980.

896 [26] F.D. Lydon, R.V. Balendran, Some observations on elastic properties of plain concrete, 897 Cem. Concr. Res. 16 (1986) 314-324.

898 [27] H. Eskandari-Naddaf, R. Kazemi, ANN prediction of cement mortar compressive 899 strength, influence of cement strength class, Constr. Build. Mater. 138 (2017) 1-11.

900 [28] B. Lothenbach, T. Matschei, G. Möschner, F.P. Glasser, Thermodynamic modelling of 901 the effect of temperature on the hydration and porosity of Portland cement, Cem. Concr. Res. 38 902 (2008) 1-18.

903 [29] A.A. Ramezanianpour, Cement Replacement Materials: Properties, Durability, 904 Sustainability, Springer, Berlin, Germany, 2014.

905 [30] T. Ikumi, I. Segura, S.H.P. Cavalaro, Influence of early sulfate exposure on the pore 906 network development of mortars, Constr. Build. Mater. 143 (2017) 33-47.

907 [31] G.W. Scherer, Stress from crystallization of salt, Cem. Concr. Res. 34 (2004) 1613-1624.

908 [32] M. Steiger, Crystal growth in porous materials-I: The crystallization pressure of large 909 crystals, J. Cryst. Growth 282 (2005) 455-469.

910 [33] M. Steiger, Crystal growth in porous materials-II: Influence of crystal size on the 911 crystallization pressure, J. Cryst. Growth 282 (2005) 470-481. 
912 [34] R.J. Flatt, G.W. Scherer, Thermodynamics of crystallization stresses in DEF, Cem.

913 Concr. Res. 38 (2008) 325-336.

914 [35] R.B. de Boer, On the thermodynamics of pressure solution-interaction between chemical 915 and mechanical forces, Geochim. Cosmochim. Ac. 41 (1977) 246-256.

916 [36] D. Min, T. Mingshu, Formation and expansion of ettringite crystals, Cem. Concr. Res. 24 917 (1994) 119-126. 